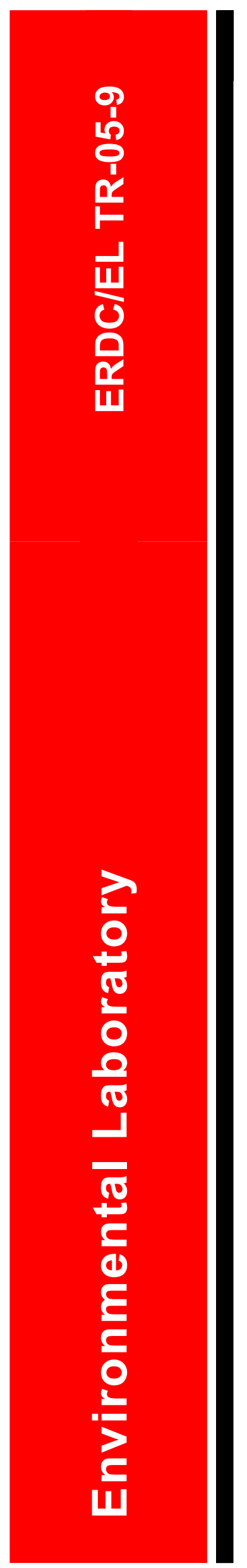

Countermine Phenomenology Program

\title{
Use of a High-Resolution 3D Laser Scanner for Minefield Surface Modeling and Terrain Characterization: Temperate Region
}

Sam S. Jackson and Michael J. Bishop

August 2005

US Army Corps of Engineers ${ }_{\circledast}$

Engineer Research and Development Center 


\section{Use of a High-Resolution 3D Laser Scanner for Minefield Surface Modeling and Terrain Characterization: Temperate Region}

Sam S. Jackson, Michael J. Bishop

Environmental Laboratory

U.S. Army Engineer Research and Development Center

3909 Halls Ferry Road

Vicksburg, MS 39180-6199

Final report

Approved for public release; distribution is unlimited 


\begin{abstract}
The use of a high-resolution, ground-based 3D laser scanner was recently evaluated for terrestrial site characterization of variable-surface minefield sites and generation of surface and terrain models. The instrument used to conduct this research was a Leica HDS3000 3D laser scanner. The high-speed, highly accurate ranging system has a $360 \mathrm{deg}$ horizontal $\times 270 \mathrm{deg}$ vertical field of view that delivers positional, range, and angular (vertical and horizontal) single point accuracies (range 1 to $50 \mathrm{~m}$ ) of $6 \mathrm{~mm}, 4 \mathrm{~mm}$, and 60 micro-radians, respectively. The laser is a class 3R and is completely eye-safe with a wavelength of $523 \mathrm{~nm}$ and spot size of $\leq 6 \mathrm{~mm}$ at a distance of $50 \mathrm{~m}$. The pulse rate is 1,000 points/ sec with an optimal effective range up to $100 \mathrm{~m}$ which is capable of producing a maximum point cloud spacing of $1.2 \mathrm{~mm}$ in the horizontal and vertical direction. Two study sites located in the midwestern United States were used for this analysis. A very dense vegetation site (Grass Site) and a bare soil site with intermittent rocks and sparse vegetation (Dirt Site) were selected for data collection to simulate both obscured and semi-obscured minefield sites. High-density scans (range 0.2 to $2.0 \mathrm{~cm}$ spacing) were utilized for Cyra target acquisition and were commensurate with size and distance to target from scanner location. Medium-density scans (range 2.0 to $5.0 \mathrm{~cm}$ spacing) were chosen for point cloud generation of the entire site(s) with approximately 10 percent edge overlap between field scans. In order to provide equivalent, unobstructed viewing perspectives from all scan locations at each site, the scanner was positioned on a trailer-mounted, chain-driven lift and raised to an approximate scan height of $7.6 \mathrm{~m}$ above the ground. Final registration to UTM projected coordinate system of the multiple scan locations for the Dirt Site and Grass Site produced mean absolute errors of 0.014 and $0.017 \mathrm{~m}$, respectively. The laser scanner adequately characterized surface roughness and vegetation height to produce contour and terrain models for the respective site locations. The detailed scans of the sites, along with the inherent natural vegetation characteristics present at each site, provide real-time discrimination of minefield site components under contrasting land surface conditions.
\end{abstract}

DISCLAIMER: The contents of this report are not to be used for advertising, publication, or promotional purposes. Citation of trade names does not constitute an official endorsement or approval of the use of such commercial products. All product names and trademarks cited are the property of their respective owners. The findings of this report are not to be construed as an official Department of the Army position unless so designated by other authorized documents. 


\section{Contents}

Preface

SF 298

\section{List of Figures}

Figure 1. Tie point generated from precise Cyra target acquisition ............5

Figure 2. Graphical depiction of scanned Dirt Site showing M20

surface mines and fiducial markers ............................................6 
Figure 3. Illustration of Cyclone georegistration process for Dirt Site depicting synchronized windows of corresponding ScanWorlds with disabled tie point constraint (DBM1)

Figure 4. Gound elevation contour map (10-cm Interval) detailing the micro topography representative of the Dirt Site... 12

Figure 5. Vertical view of Grass Site depicting vegetation height in meters 13

Figure A1. Final Registration Diagnostics_UTMxyzDS.txt ......................A1

Figure A2. Interim Registration Diagnostics_DS.txt ................................A2

Figure A3. Final Registration Diagnostics_UTMxyzGS.txt .....................A3

Figure A4. Interim Registration Diagnostics_GS.txt ...............................A4

Figure B1. Cyra scan logs/field sketches .................................................. B2

Figure C1. Trailer-mounted setup of Leica HDS3000 3D Laser Scanner elevated $7.62 \mathrm{~m}$ above Grass Site (viewed from southwest looking northeast, taken 26 July 2004) 


\section{Preface}

This report was prepared for the U.S. Army Engineer Research and Development Center's (ERDC) Countermine Phenomenology Program. The technical monitor at the time of publication was Mr. Jerrell R. Ballard, Jr., Environmental Laboratory (EL), ERDC.

The work was performed under the direction of the Ecosystem Evaluation and Engineering Division (EE), EL, and was funded under the Site Characterization work unit with Mr. Thomas E. Berry as the EE Principal Investigator. The EL Principal Investigator for this analysis was Mr. Sam S. Jackson, EE, and coinvestigator was Mr. Michael J. Bishop, EE. Program Manager for the ERDC Countermine Phenomenology Program was Dr. Larry N. Lynch of the Geotechnical and Structures Laboratory, ERDC.

Many individuals contributed to the support of this project, including the following: Messrs. Ballard and Berry; Mr. David L. Leese, Information Technology Laboratory, ERDC; Ms. Elizabeth Lord, Computer Sciences Corporation; and Mr. R. Eddie Melton, Jr., JAYA Corporation. Dr. Edwin A. Theriot was Director, EL, and Dr. David J. Tazik was Chief, EE.

At the time of publication, COL James R. Rowan, EN, was Commander and Executive Director of ERDC. Dr. James R. Houston was Director. 


\section{Introduction}

\section{Purpose}

This measurement and analysis effort was conducted to support specific key objectives of the Engineer Research and Development Center's (ERDC) Countermine Phenomenology Program. The objectives addressed through this research primarily include the development of an improved knowledge of geoenvironmental phenomenology factors impacting both mine and minefield detection in various operational environments and help support the development of algorithms using these factors to improve detection capability of both surface and buried mines and minefields.

The use of a high-resolution 3D ground-based laser scanner was evaluated and assessed for characterizing and capturing terrestrial site characteristics of variable-surface minefields to aid in surface model generation and ground surface contour mapping. This research tool is one of many being implemented by the ERDC Countermine Phenomenology Program to evaluate potential methods for characterizing and delineating background features within minefields. This effort is intended to support and improve the understanding of background phenomenology with respect to minefields (Jackson et al. 2005).

\section{Background}

The highly accurate and dense point data (or point clouds) captured by terrestrial 3D laser scanners, such as the Leica HDS3000 system, allow for the development of robust datasets for GIS modeling efforts and dynamic landscape visualization. The ground-based instrument is closely akin to its airborne light detection and ranging (LIDAR) counterpart. However, terrestrial LIDAR is acquired with more efficiency at a much higher resolution from a more stable platform. Eliminating the need to correct for orientation errors common with airborne sensors, terrestrial 3D laser scanners produce accuracy measured in millimeters as opposed to centimeters, but for obvious reasons are not as effective as airborne LIDAR at extracting data in the vertical dimension, such as vegetation height and ground surface elevation. Other limiting factors of groundbased LIDAR are its restriction to small geographic areas and the requirement of numerous scans, which can become labor-intensive for large area acquisitions.

Multiple laser scanner setups, analogous to airborne LIDAR swaths, are required for data acquisition when implementing terrestrial LIDAR and must be 
coregistered to form a cohesive point cloud representative of the sampled area. Laser scanning, in general, is a rapid non-invasive form of data acquisition that is suitable for characterizing areas with restricted or limited access or where environmental conditions exist that may limit one's ability to gain physical access to the area.

Airborne laser scanner systems are abundant on the market today and the technology is considered to be in a mature state. These laser systems are very complex, being more a geodetic system for data acquisition and more a photogrammetric system for data processing (Axelsson 1999). What is lacking, however, is the development and refinement of algorithms and data interpretation methods to provide various surface representations of the scanned area. Likewise, little is known about the implications for surface modeling from the use of terrestrial laser systems.

Terrestrial LIDAR - being active sensing devices that emit electromagnetic energy either in the visible or near infrared part of the spectrum - records the amount of reflectance and laser beam return time from the scanned feature. The surveyor can define the area of interest and specify the angular resolution value, with no further attendance required during the scanning phase, which takes only minutes to complete. Linear resolution over the object depends on distance, azimuth, and elevation of the laser beam, as well as terrain surface morphology. The accuracy of point positioning is a function of distance, the number of scanning repetitions, and laser spot-size (Colombo 2003).

Johansson (2002) documented undesirable artifacts in resulting point cloud data generated from various ground-based laser scanners. Strange effects along edges of objects and difficulty in capturing points on certain surfaces were noted. The author emphasizes small spot size, good range capabilities, and high positional accuracy of the chosen scanner to minimize or resolve these issues.

Guarnieri et al. (2004) described the insufficient use of natural objects as control points for model georeferencing and emphasized common error sources when using ground-based LIDAR. Detected errors were directly related to the scanner's accuracy, intensity response from the reflected laser beam, and the operator's ability to identify model control points. The authors advise the use of artificial reference targets ${ }^{1}$ whenever possible to increase the accuracy of control point selection. These fixed targets can be surveyed and will therefore lend proper fitting procedures during the point cloud registration.

\footnotetext{
1 Targets defined herein as scanner reference targets (Cyra targets) used for control point
} acquisition during laser data registration. These are not the same as landmine targets. 


\section{Study Methods and Data Processing}

\section{Site Description}

Two variable-surface minefield sites located in the mid-western United States were selected as study site locations to conduct this research effort. A very densely vegetated site (Grass Site) and a mostly bare soil site ${ }^{1}$ (Dirt Site), with intermittent rocks and sparse vegetation, allowed for characterization efforts to be employed for obscured and semi-obscured minefields. Each site is approximately rectangular having four-sided, right-angled polygons with opposite sides equal and parallel to each other. The dimensions of the Grass Site and Dirt Site are $40 \times 160 \mathrm{~m}$ and $40 \times 320 \mathrm{~m}$, respectively. Both minefield sites serve as test beds for deployed mines and contain M20, M19, and RAAM buried and surface emplaced mines with top hat and Electro-Optical Infrared (EOIR) red board fiducial markers spaced at various intervals.

The Grass Site has about a 5 to 10 percent grade with a northwest-facing slope. It is comprised mostly of thick grass with varying density and distribution over the field. In contrast, the Dirt Site is relatively flat, with the exception of a drainage ditch oriented north and south across the center of the field on the east side. The Dirt Site has been plowed several times and consists mainly of large boulders and smaller rocks with sparse patches of grass vegetation. The basic capability to derive contour and terrain models from a high-density laser data point cloud was evaluated for these two geophysically different sites.

\section{Laser Data Collection}

Data acquisition took place during late July and early August 2004. A Leica HDS3000 3D laser scanner manufactured by Leica Geosystems HDS, Inc. (formerly Cyra Technologies) was used to provide a high-definition survey of both sites. The SmartScan Technology ${ }^{\mathrm{TM}}$ of this unit provides a maximum 360 deg horizontal field of view and a maximum 270 deg vertical field of view. The scanner emits rapid pulses of green $(523 \mathrm{~nm})$ laser light that sweeps across the landscape and sends back numerous measurements with precise $\mathrm{x}, \mathrm{y}$, and $\mathrm{z}$ coordinates, each having an associated RGB color and intensity value. The sophisticated design of the scanner enables point clouds to be captured that

1 Named "Dirt Site" by Army test bed sponsor. 
correspond to true point positions where the laser pulse hits the object. The point cloud represents the shape and position of the objects scanned relative to the position of the scanner (Leica Geosystems HDS, Inc. 2004). See Table 1 for a complete summary of the scanner specifications.

\begin{tabular}{|l|l||}
\hline \multicolumn{2}{|l||}{ Table 1 } \\
Specifications for the Leica HDS3000 3D Laser Scanner \\
\hline \hline Field of View & $360 \mathrm{deg} \mathrm{H} \times 270 \mathrm{deg} \mathrm{V}$ \\
\hline Positional Accuracy & $6 \mathrm{~mm}$ at $50 \mathrm{~m}$ \\
\hline Wavelength & $523 \mathrm{~nm}$ \\
\hline Spot Size & $\leq 6 \mathrm{~mm}$ at $50 \mathrm{~m}$ \\
\hline Pulse Rate & 1,000 points/sec effective to $100 \mathrm{~m}$ \\
\hline Maximum Sample Density (spacing) & $1.2 \mathrm{~mm}$ \\
\hline
\end{tabular}

The operating software used in conjunction with the laser scanner during data acquisition was Cyclone Version 5.0. The Cyclone software assists the surveyor in capturing point cloud data, visually interpreting and processing these data, then integrating the collected information into useful geospatial formats.

When feasible, the scanner was positioned at approximately one-quarter length intervals along each field's long side in an effort to provide uniform scan coverage of the entire site. Also, to obtain an unobstructed viewing angle from all scanner locations, the scanner was positioned on a trailer-mounted, chain-driven lift and raised to a scan height of $7.62 \mathrm{~m}$ above the ground. At each initial fixed scanner position, a high-resolution picture image of the viewing area was captured using the scanner's built-in camera. This allowed the surveyor to easily view and depict areas to be scanned, making Cyra target acquisition and site/ minefield scans much more efficient.

\section{Cyra target acquisition}

After a suitable image was acquired at each scanner setup, all corresponding Cyra targets within the effective scan range $(<100 \mathrm{~m})$ were probed with the scanner prior to acquisition to determine the approximate distance to the target. High-density laser scans (range 0.2 to $2.0 \mathrm{~cm}$ spacing) were used for Cyra target acquisition and were commensurate with size and distance to the target from each scanner setup. The tie points generated from each target acquisition (Figure 1) established a set of constraints that were used to register, or geometrically align, all of the scanner locations into a single, fitted point cloud representing each site. Each tie point was labeled with a unique registration ID.

To obtain a tie point with minimal deviation from the center of the target, the target must be scanned with a sufficient density of postings in the object's center. Once a post point is manually selected that is close to the target's center, the scanner performs a coarse scan to locate the center circle then proceeds with a fine scan ( $\sim 1.2 \mathrm{~mm}$ spacing at $50 \mathrm{~m})$ using an algorithm to locate the exact center. 


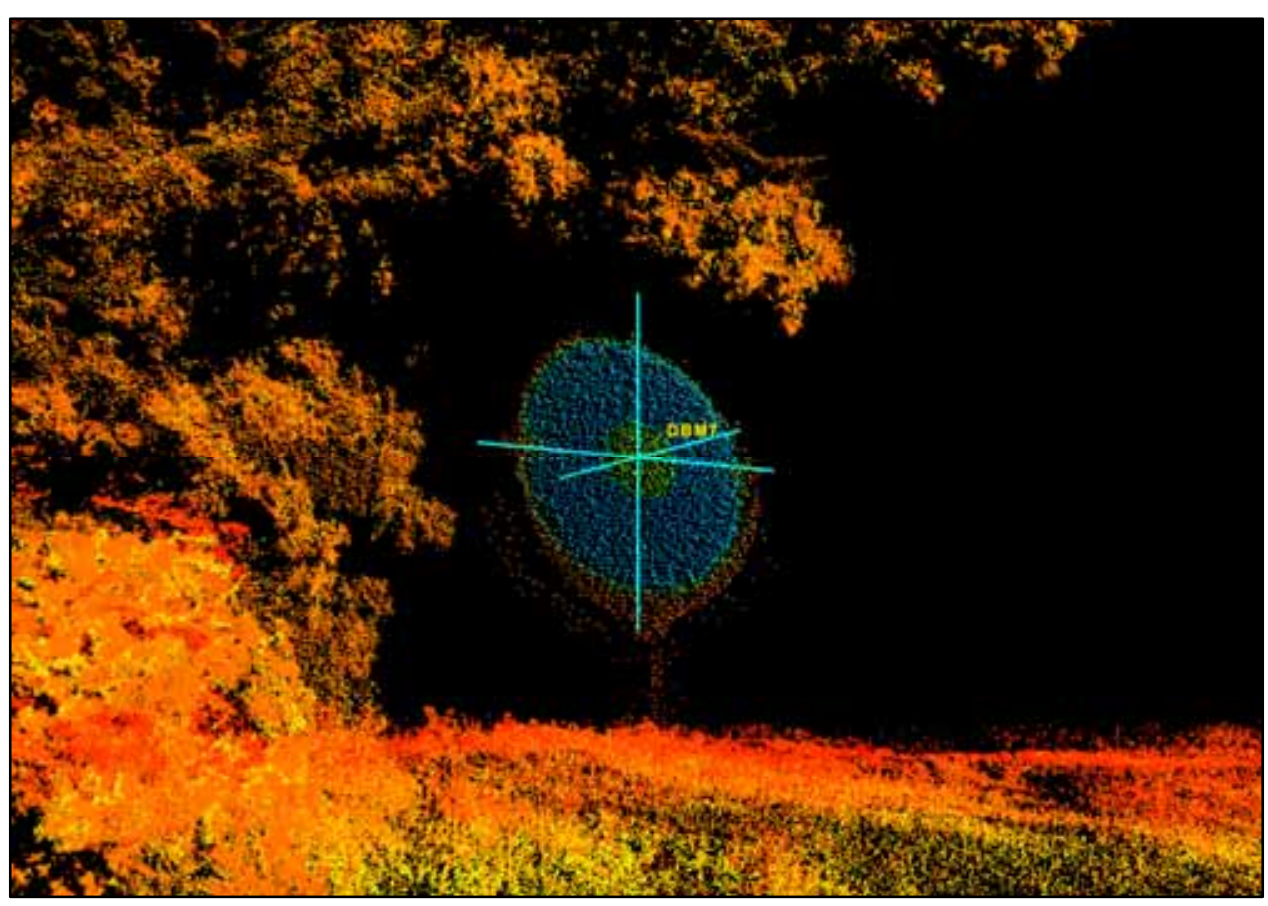

Figure 1. Tie point generated from precise Cyra target acquisition. Posting color represents multi-hue intensity of each laser return. High intensity appears blue and low intensity appears red

A vertex is placed at the perceived center of the Cyra target, representing the tie point. A minimum of three Cyra targets was placed at each scanner setup to produce sufficient tie points to be used as constraints in the registration process. Each Cyra target was strategically positioned at opposite extents of the minefield site and served as common targets to additional scanner setups in order to successfully reference each point cloud together.

\section{Site/minefield scans}

After target acquisition was complete at each scanner setup, the sites were scanned. The laser scanner was positioned at four locations at the Grass Site, two on the western-most side and two on the eastern-most side of the minefield. Restricted access on the north side of the Dirt Site prevented laser scan setups on this side. As a result, the scanner was positioned only on the south side and provided six total setups on the Dirt Site. Moderate-density scans were chosen for point cloud generation of each site with approximately 10 percent edge overlap at each field extent to capture the entire area of interest. Also, a 10 percent scan overlap between site scans ensured sufficient point cloud data collection for each site. The Grass Site and the Dirt Site were scanned at approximate post spacings of 5 and $2 \mathrm{~cm}$, respectively, in the horizontal and vertical direction. Figure 2 depicts a small portion of the scanned Dirt Site and illustrates the point cloud representation of the various mines and fiducial markers in the minefield. 


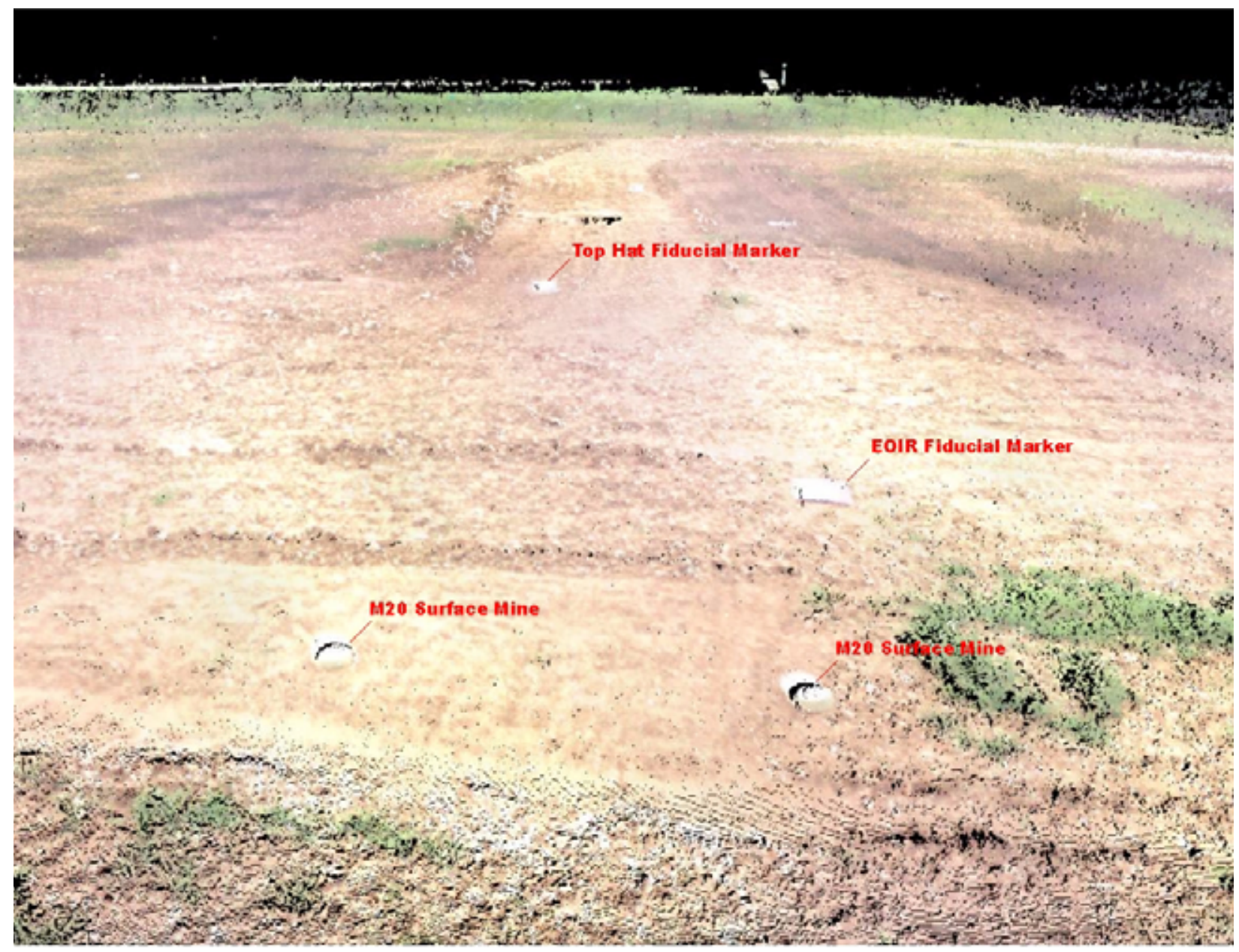

Figure 2. Graphical depiction of scanned Dirt Site showing M20 surface mines and fiducial markers. True-color laser postings are spaced every $2 \mathrm{~cm}$

\section{Data Analysis}

Once data acquisition was completed for both sites, processing of the laser data began. To generate a three-dimensional, continuous point cloud representation of each site, each scanner setup location's point cloud, or ScanWorld, had to be coregistered with one another (interim registration) and referenced to a common coordinate system (georegistration) for use with other spatial datasets and to perform additional analyses. A ScanWorld can be defined as a collection of scanned point clouds that are derived from consecutive scans at the same scanner location. The ScanWorlds were aligned together to form a referenced dataset representative of a particular site. The fully georegistered scan data were then processed to produce digital elevation and terrain models applicable to each site. Further descriptions of these post-processing techniques are detailed below. 


\section{Laser data registration}

Registration is a method that aligns many individual ScanWorlds into a single georeferenced ScanWorld to represent the entire area of interest, in this case each minefield site. The registration process makes use of various mathematical algorithms that compute the optimal alignment transformations for each ScanWorld in the registration such that the constrained objects or point clouds are aligned as closely as possible in the resulting ScanWorld (Leica Geosystems HDS, Inc. 2004). Because sufficient Cyra targets were acquired for all ScanWorlds at each site, target-based registration was used for interim point cloud alignment. The Cyra targets placed at the extent of each minefield served as control or tie points in the registration process. These tie points that were common to adjacent ScanWorlds, appearing to be in the same Cartesian location ( $\mathrm{x}, \mathrm{y}$, and $\mathrm{z}$ position), were fitted together to establish an accurate relationship between each of the ScanWorld point clouds. During this initial registration process, the Cyclone software added tie points as constraint objects to be paired with corresponding tie points in other ScanWorlds. The software performs a constraint-searching algorithm that locates objects with the same registration ID, or tie points that are geometrically consistent, to find the optimal solution.

After the ScanWorlds were registered together for each site, the single point cloud was georegistered to the Universal Transverse Mercator (UTM) projection on the basis of the North American Datum 1983 (NAD83). Surveyed coordinates of specific Cyra targets used in the registration process were collected to millimeter accuracies with a Real Time Kinematic (RTK) Global Positioning System (GPS) at each site and were used to register the existing point cloud data to the UTM projected coordinate system. Each target's Cartesian position was identified to minimum accuracies of $10 \mathrm{~mm}$ horizontal and $15 \mathrm{~mm}$ vertical. At least four surveyed Cyra targets with known coordinates were used for each site, and these corresponded to all relative ScanWorlds. A text file containing the Northing, Easting, and Elevation measurements associated with each surveyed Cyra target was imported into the Cyclone software. The imported survey coordinates served as a new survey control ScanWorld to which all others ere then georegistered. The surveyed Cyra targets were positioned to achieve a large aspect ratio and thus provide an optimal geometric solution in the registration process. After successful georegistration was completed for both sites, surface analysis techniques were employed to further characterize the sites and their associated backgrounds.

\section{Surface/terrain analysis}

Topographic derivatives were generated for each site to effectively relate the scanned laser data to terrain features. The abundance of data points generated from the laser scanner allowed for the production of detailed digital terrain and elevation model representations of each site. These terrain models not only provide 3D visualization of the background phenomenology but also enable analysts to measure topographic variations within the minefield. 
The georegistered data points representing the area of interest at each site were extracted and unified as a single point cloud for processing. Scan data outside the fence area, or beyond the extent of each minefield, were discarded from the data set prior to processing to remove trees and other superfluous background data. Tall vegetation within the Dirt Site was manually extracted by similar means for generation of a bare earth model. Subsequent generation of a contour map from the bare earth model was produced for the Dirt Site as well. In addition, a vegetation height model was produced from the laser point cloud representing the Grass Site.

The Cyclone software was used to select five to nine individual laser data points representative of relatively flat, bare ground from a centralized area within the Dirt Site point cloud. Data for these sites were used as input for a region grow, surfacing algorithm. The surface-smoothing algorithm segments the point cloud to form a horizontally expanded, planar point cloud indicative of the terrain geometry. The algorithm operates based on fit calculation parameters that are user-specified and continues until all assumed non-ground data points are effectively isolated from the remaining ground points. The primary surface parameters involved in this process include (a) region thickness threshold, which defines the range of data points to be surfaced as ground, (b) surface angle tolerance to account for areas of high relief, and (c) gap distance, which defines the maximum distance allowed between parts of the same smooth surface. The region grow algorithm did not properly identify certain points within the Dirt Site. Therefore, these point data were manually edited until satisfactory results were obtained.

After all assumed vegetation was removed and the ground surface points were identified for the Dirt Site, the points representing bare ground were used to create a Triangulated Irregular Network (TIN) or mesh. By producing a TIN of the assumed ground, a coherent modeled surface can be easily visualized. An elevation contour map was subsequently produced from the TIN for the Dirt Site. Major contours were specified at 0.5-m intervals, and the number of minor intervals per major contour was set at five. As a result, this produced index contours at half-meter intervals and a contour interval of $10 \mathrm{~cm}$, effectively yielding a highly detailed, micro topographical profile of the Dirt Site. A regularly spaced sample grid was then generated from the original TIN layer to provide a digital terrain model of the Dirt Site.

Due to the dense vegetation present at the Grass Site, a vegetation height map was produced to better quantify the background component of the site. The laser data points representative of the Grass Site were exported from the Cyclone software as an $\mathrm{x}, \mathrm{y}$, and $\mathrm{z}$ text file. This text file was imported into a custom, proprietary application written specifically for this vegetation height extraction (personal communication, R. E. Melton, Jr., Senior Programmer, JAYA Corporation 2004). The application was designed to distinguish and isolate assumed ground hits and maximum vegetation height points. The application extracts laser data from the lowest 10 percentile using each point's elevation (z) value and then averages those within a one square meter cell size. This is the assumed ground. Likewise, laser data from the top 10 percentile were extracted by $z$ value, averaged, and then output as a single point representing the average maximum vegetation height for that $1-\mathrm{sq}-\mathrm{m}$ cell. The output, $\mathrm{x}$ and $\mathrm{y}$ values for the center of each cell and an average elevation value, were uploaded into an 
ESRI point shapefile. Vegetation height was calculated by subtracting the assumed ground elevation points from the assumed vegetation elevation points. These new elevation point values were the representative vegetation height value for each one-meter cell center, which were used to generate a 1-m grid of the entire Grass Site. 


\section{Results and Discussion}

\section{Laser Data Registration}

Mean Absolute Error (MAE) was used to measure the accuracy of the point cloud registrations for each site (Table 2). Point cloud alignment error was evaluated for both the interim registration and georegistration to the UTM projected coordinate system using the RTK-GPS collected survey coordinates.

\begin{tabular}{|c|c|c|c|}
\hline \multicolumn{4}{|c|}{$\begin{array}{l}\text { Table } 2 \\
\text { MAE Values for Interim Point Cloud Registration and } \\
\text { Georegistration for Both Sites }\end{array}$} \\
\hline \multirow[b]{2}{*}{ Minefield Site } & \multicolumn{2}{|c|}{ Registration Error (MAE) } & \multirow[b]{2}{*}{ \# ScanWorlds } \\
\hline & Interim & Geo (UTM) & \\
\hline Dirt Site & $0.008 \mathrm{~m}$ & $0.014 \mathrm{~m}$ & 6 \\
\hline Grass Site & $0.014 \mathrm{~m}$ & $0.017 \mathrm{~m}$ & 4 \\
\hline
\end{tabular}

MAE can be defined as the weighted average of the absolute errors, with the relative frequencies as the weight factors. Additionally, the minimum MAE value can be interpreted as the mean absolute deviation among data points. All tie point constraints were equally weighted during the registration process. One constraint pair, a target tie point (DBM1) and its corresponding survey coordinate, was disabled in the final georegistration of the Dirt Site because of the inordinate error compared to all other constraints (Figure 3). See Appendix A for complete registration diagnostics for both minefield sites.

The Positional error of the Leica scan data alone is generally around $6 \mathrm{~mm}$ (Leica Geosystems HDS, Inc. 2004). However, the overlap measurements are often imprecise, especially for scans of complex geometry such as grass and other vegetation. Various reasons exist that could explain this intricacy. Overlapping laser points are often not always from the same surface, or blade of grass. Multiple viewpoints from different, surrounding ScanWorlds generate a somewhat convoluted perspective of the same spatial area, particularly for grass or vegetation scans, therefore increasing the point-to-point deviation or error. Other reasons may exist including environmental factors such as wind or sun angle, which may cause vegetated surfaces to be more spatially variable between consecutive scans, contributing to a higher MAE. Moderate winds during a portion of the Grass Site data capture contributed to lift platform and scanner 


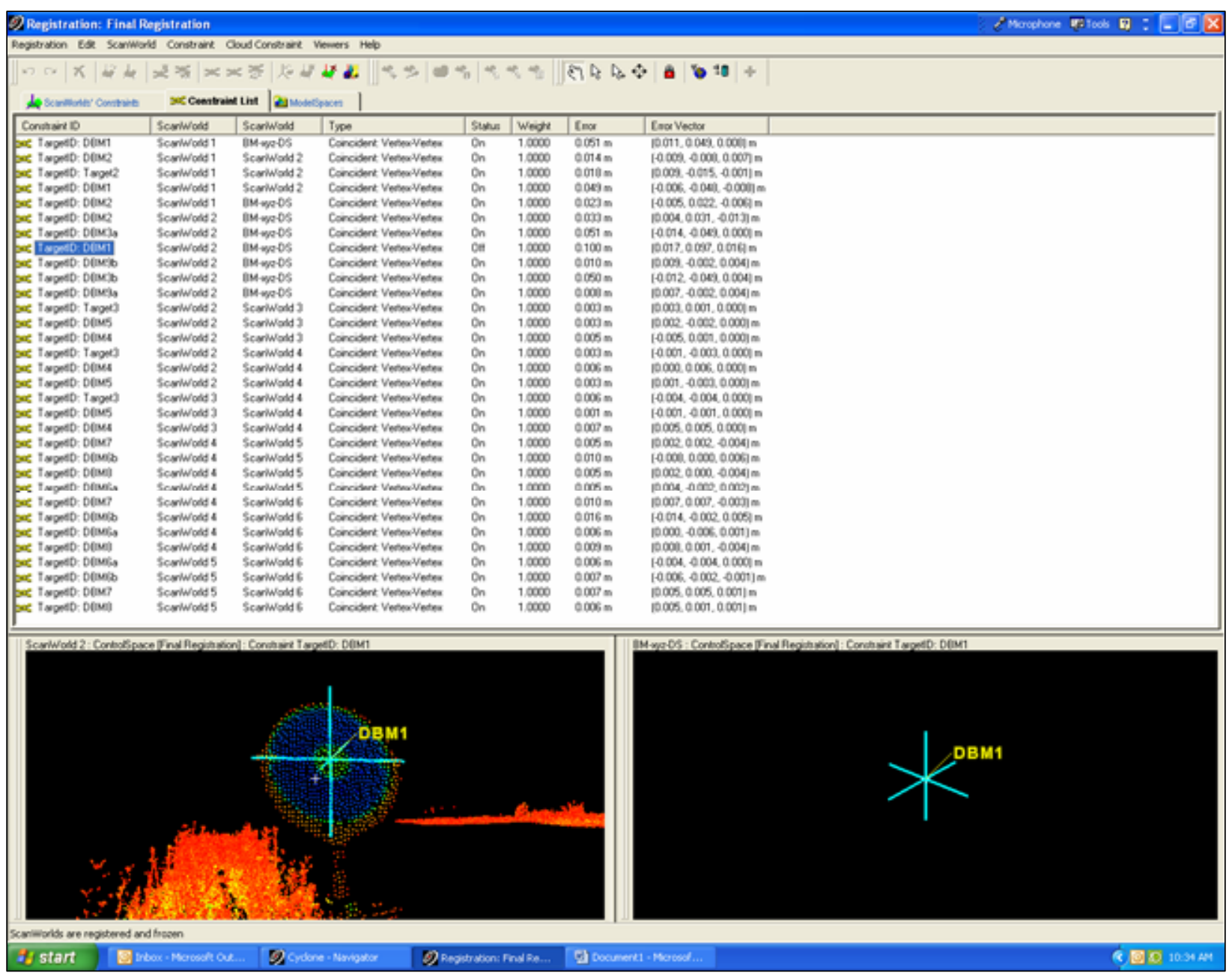

Figure 3. Illustration of Cyclone georegistration process for Dirt Site depicting synchronized windows of corresponding ScanWorlds with disabled tie point constraint (DBM1)

sway, making precise tie point acquisition much more difficult. Also, radiant heat energy from the intense mid-day sun during the same scanning operation produced an evident "wavy" pattern in a portion of the scan data. It is speculated, therefore, that these were the primary known causes of the higher error for the Grass Site $(0.017 \mathrm{~m})$ when compared to the Dirt Site $(0.014 \mathrm{~m})$.

\section{Surface/Terrain Analysis}

Terrestrial 3D laser characterization efforts of the variable-surface sites yielded an elevation contour map and vegetation height model of the Dirt Site and Grass Site, respectively. Figure 4 illustrates the resulting ground surface elevation contour map, with contour intervals of $10 \mathrm{~cm}$. 


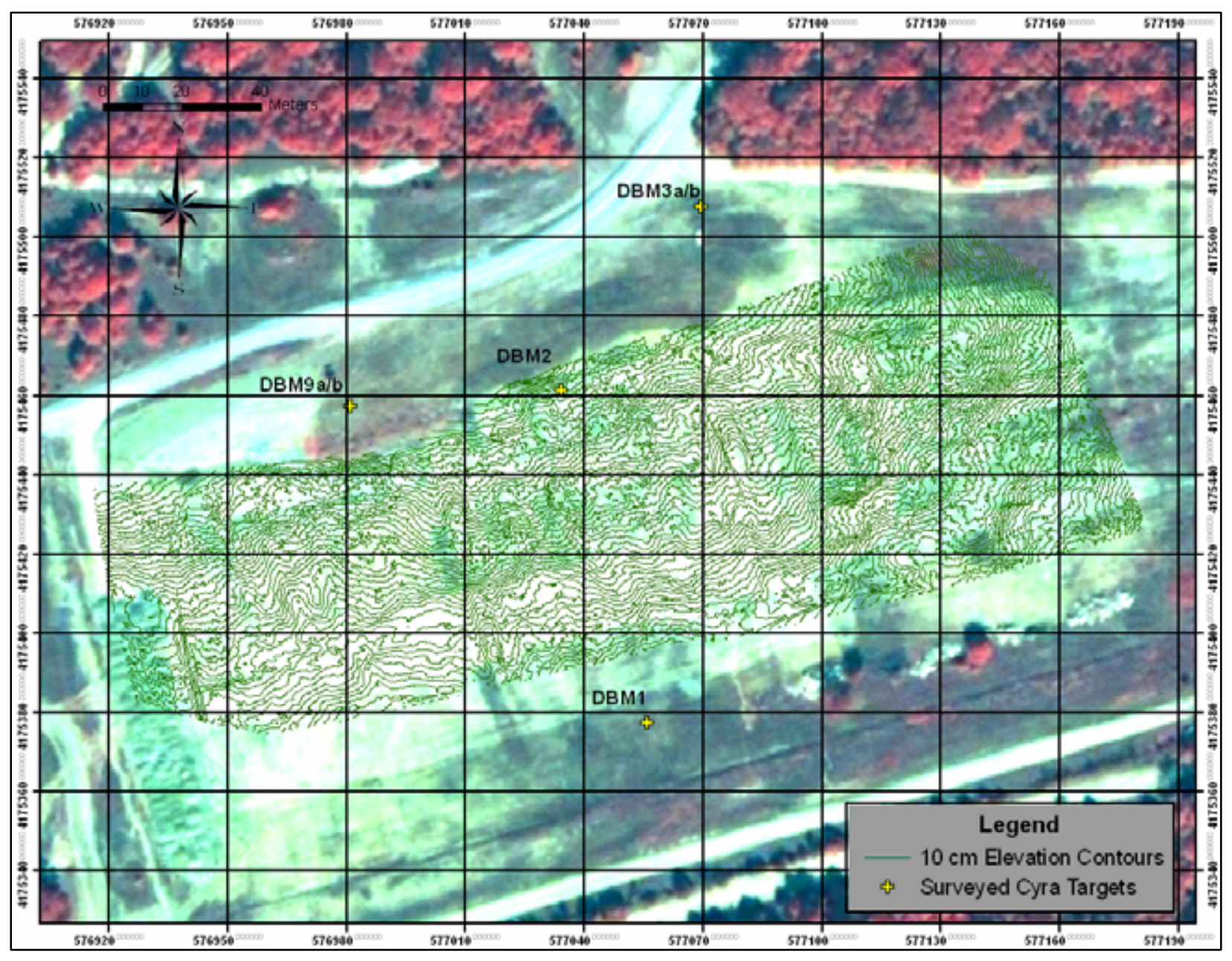

Figure 4. Gound elevation contour map (10-cm Interval) detailing the micro topography representative of the Dirt Site

The abundance of data points generated from the laser scanner provided a very rich data set from which to produce a very detailed micro topographical contour map of the Dirt Site. By producing a 10-cm contour interval map, the vertical relief and landscape profile of the site were accurately depicted. The contour interval measurement chosen produced a minimum vertical distance between adjacent contour lines, allowing for precise modeling capabilities of the terrain surface.

A vegetation height model, generated from the closely spaced laser data points, effectively characterized the very dense vegetative component of the Grass Site (Figure 5). Notice the high tree crown tops represented in red on the extreme northern and southwestern parts of the Grass Site. Inspection of the resulting vegetation surface revealed the variation in vegetation height differences across the site. 


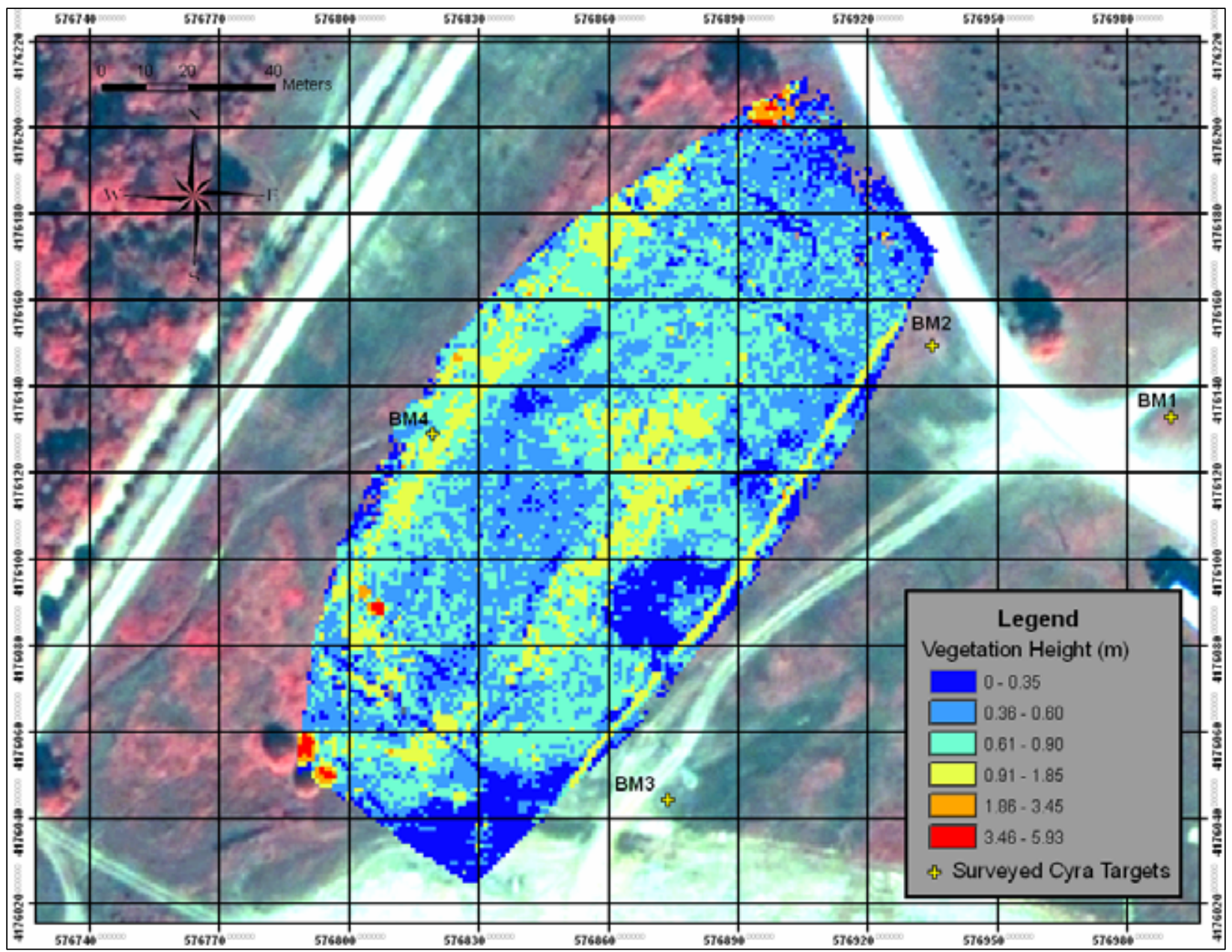

Figure 5. Vertical view of Grass Site depicting vegetation height in meters. The image portrays a chromatic sequence with lower vegetation heights appearing blue and higher vegetation heights appearing red 


\section{Future Considerations}

A primary objective of this research was to characterize various backgrounds (sand, rock, grass, soil, etc.) typically present in a minefield and evaluate the effectiveness of utilizing a laser scanning device to accomplish this task. It may be apparent with additional research that a smaller area can be scanned to produce similar results and satisfy program objectives while minimizing registration error. If successful, this would significantly reduce the amount of data collected and save a great amount of time. Registration error could also be reduced by restricting Cyra target and laser measurement acquisitions to within $75 \mathrm{~m}$, well within the stated effective range of the scanner $(100 \mathrm{~m})$.

Due to the oblique, off-nadir measurement angle of the elevated scanner, vertical measurements of scanned objects are not effectively obtained. To better determine the terrestrial scanner's ability to accurately extract vegetation heights in a minefield, a ground-truth exercise should be implemented to develop a control measurement of vegetation heights to compare to the scanner data estimates. In addition, the related estimation of assumed "ground" at a vegetated site using an average of $\mathrm{z}$ values in the lowest tenth percentile of points for a unit area is a methodology that should be field validated. 


\section{References}

Axelsson, P. (1999). "Processing of laser scanner data—algorithms and applications," ISPRS Journal of Photogrammetry and Remote Sensing 54(2-3), 138147.

Colombo, L. (2003). "Terrestrial laser imaging: A technique in progress," Geomatics World 11, 5.

Guarnieri, A., Vettore, A., and Remondino, F. (2004). "Photogrammetry and ground-based laser scanning: Assessment of metric accuracy of the 3D model of Pozzoveggiani Church," FIG Working Week, May 22-27, Athens, Greece.

Jackson, S., Bishop, M., Leese, D., and Lord, E. (2005). "High-Resolution 3D laser imaging of various surfaces in minefields and implications for surface modeling." Detection and Remediation Technologies for Mines and Minelike Targets. Proceedings of the SPIE Defense and Security Symposium, Orlando, FL, March 28 - April 1.

Johansson, M. (2002). "Explorations into the behavior of three different highresolution ground-based laser scanners in the built environment." Close Range Imaging-Long Range Vision. Proceedings of the ISPRS Commission V Symposium, Corfu, Greece, 1-2 September 2002.

Leica Geosystems HDS, Inc. (2004). Cyra Technologies HDS training manual. 


\section{Appendix A Registration Diagnostics}



Scanworld Transformations

translation: (4175364.153,577001.415, 342.135) m

rotation: $(-0.0043,0.0047,-1.0000): 71.050$ deg

Scanworld 2. (4175402.145, 577100,966, 342.303) translation: $(4175402.145,577100.966,342.303)$
rotation: $(-0.0073,0.0047,-1.0000): 69.08 \dot{5}^{3} \mathrm{deg}$ rotation: $(-0.0073,0.0047,-1.0000): 69.085$ deg translation: $(4175430.434,577218.713,340.909)$
rotation: (0.0009, $0.0074,-1.0000): 168.915$ deg Scanworld 4

translation: $(4175431.397,577219.363,340.954) \mathrm{m}$ rotation: translation: (4175451.473, 577313,238, 346.698) m rotation: $(-0.0079,0.0115,-0.9999): 92.921 \mathrm{deg}$

Scanworld 6. (4175498.617,577303.640,347.103) translation: $(4175498.617,577303.640,1347.103){ }^{m}$
rotation: (-0.0079, 0.011i, -0.9999$): 122.630 \mathrm{deg}^{\mathrm{m}}$ Scanworld BM-Xyz-D

rotation: $(0.0000,1.0000,0.0000): 0.000 \mathrm{deg}$

unused controlspace objects

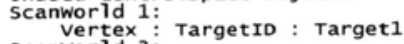

Scanworld 3: TargetID : DBM4

scanworld 4

vertex : TargetID : Target 4

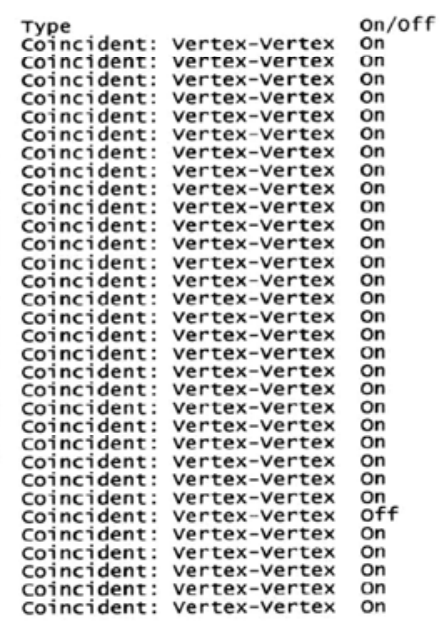

weight
1.0000
1.0000
1.0000
1.0000
1.0000
1.0000
1.0000
1.0000
1.0000
1.0000
1.0000
1.0000
1.0000
1.0000
1.0000
1.0000
1.0000
1.0000
1.0000
1.0000
1.0000
1.0000
1.0000
1.0000
1.0000
1.0000
1.0000
1.0000
1.0000
1.0000
1.0000
1.0000

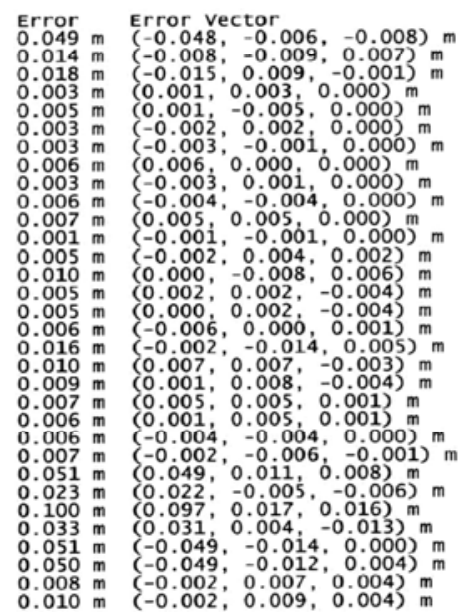

Figure A1. Final Registration Diagnostics_UTMxyzDS.txt 




Scanworld Transformations

cransiation: $(0,000,0.000,0,000)$ m
rotation: $(0.0000,1.0000,0.0000): 0.000$ deg

scanworld 2

translation: $(-3,629,106,503,0.952) \mathrm{m}$
rotation: $(-0.0673,-0.0666,0.9955) \div 1.980 \mathrm{deg}$

rotation: $(-0.0007,0.0117,-0.9999): 97.860$ deg

scanworld 4

transiation: $(7,142,227,990,0.535) \mathrm{m}$
rotation: $(0.0027,-0.0049,1.0000): 148.077 \mathrm{deg}$

rotation:

translation: $(18.621,323.252,7.015) \mathrm{m}$.

rotation: (-0.0297, $0.0179,-0.9994): 21.872 \mathrm{deg}$

translation: $(-29.086,329.476,7.388)$
rotation: $(-0.0173,0.0111,-0.9998): 51.577 \mathrm{deg}$

unused controlspace objects

scanworld 1

vertex : Targetio : Target 1

scanworld 2 :

vertex : Targetro : Dam3a

vertex : Targetio :

vertex : TargetIo : Dвм96

Scanworld 3 :

vertex : Targetio : OBM4

scanworld 4 :

vertex : Targetio : Target 4



Figure A2. Interim Registration Diagnostics_DS.txt 
Status: VALID Registration

Final Registration Diagnostics_UTMXyzGS.txt

Mean Absolute Error:

for Enabled Constraints $=0.017 \mathrm{~m}$

Date: 2004.09.10 09:11:26 $=0.000$

Database name : Grassy_Site_Tallveg

Scanworlds

Scanworld 2
scanworld 3

Scanworld 5

Scanworld
BM-xyz-GS

Constraints

Name

TargetID: $B M$

TargetID: ${ }^{\text {TM3 }}$

TargetID: Targs

TargetID: $B M$

TargetID: Targs

TargetID: ${ }^{B M 1}$

$\begin{array}{ll}\text { TargetID: } & \text { BM3 } \\ \text { TargetID } & \text { Targs } \\ \text { TargetID: } & \text { BM3 }\end{array}$

TargetrD: BM2

TargetID: BM1

TargetID: Targ5

TargetID: $\mathrm{BM}$

Targetro: BM2

TargetID: Targ5

TargetID: $B M 3$

TargetID: BM1

TargetID: BM4

TargetID: BM1

TargetID: BM2

TargetID: $B M$

TargetID: BM2

TargetID: $B M$

TargetID: $B M 33$

TargetID: BM

TargetID: $\mathrm{BM4}$

TargetID: BM2

Scanworld, Scanworld

Scanworld
Scanworld 3
Scanworld 3
Scanworld 3

on/off ccanworld

Scanworld

Coincident: vertex-vertex ccanworld 2 scanworld 5 coincident: vertex-vertex on Scanworld 2 scanworld 5 coincident: vertex-vertex on scanworld 2 scanworld 5 coincident: vertex-vertex on scanworld 2 Scanworld 5 coincident: vertex-vertex on scanworld 2 scanworld 6 coincident: vertex-vertex on scanworld 2 scanworld 6 colnctent: vertex-vertex on scanworld 2 scanworld 6 coincident: vertex-vertex on scanworld 3 scanworld 5 coincident: vertex-vertex on scanworld Scanwor 5 coincident: vertex-vertex on scanworld 3 scanworld 5 coincident: vertex-vertex on scanworld 3 scanworld 5 coincident: vertex-vertex on scanwor Scanworld 3 Scanworld 6 colncident: vertex-vertex on scanworld 3 scanworld 6 coincident: vertex-vertex on Scanworld 6 coinciont: vertex-vertex on scanworld 3 scanworld 6 coincident: vertex-vertex on scanworld 5 scanworld 6 coincident: vertex-vertex on scanworld s scanworld 6 coincident: vertex-vertex on 作 scanworld 5 scanworld 6 colncident: vertex-vertex On Scanworld 2 BM-xyz-GS Cojncident: vertex-vertex on Scanworld 2 BM-xyz-GS scanworld 2 BM-xyz-GS coincident: vertex-vertex on Scanworld 3 BM-xyz-GS Coincident: vertex-vertex on coincident: vertex-vertex on Scanworld 3 BM-xyz-GS coincident: vertex-vertex On coincident: vertex-vertex on coincident: vertex-vertex on coincident: vertex-vertex on scanworld 5 BM-xyz-GS Coincident: vertex-vertex on Coincident: vertex-vertex on Coincident: vertex-vertex on Scanworld 6 BM-xyz-GS coincident: vertex-vertex on

Scanworld Transformations

Scanworld 2

translation: (4176111.191, $576907.227,351.818) \mathrm{m}$

rotation: $(-0.0025,0.0015,-1.0000): 135.445 \mathrm{deg}$

transiation: (4176069.258, $576873.798,349.791) \mathrm{m}$

Scanworld 5

transiation: (4176128.055, 576799.248, 343.859) m rotation: $(-0.0089,-0.0070,0.9999): 64.915 \mathrm{deg}$

Scanworld 6
trans lation: (4176170.164, $576836.374,345.654) \mathrm{m}$
rotation: $(-0.0114,-0.0030,0.9999): 54.224 \mathrm{deg}$

translation: (0.000, $0.000,0.000)$

rotation: (0.0000, i. $0000,0.0000): 0.000 \mathrm{deg}$

unused controlspace objects : none

Figure A3. Final Registration Diagnostics_UTMxyzGS.txt 
Status: VALID Registration

Interim Registration Diagnost1CS_GS.txt

Mean Absolute Error:

for Enabled Constraints $=0.014 \mathrm{~m}$

Date: 2004.08.19 12:04:00

Date: 2004.08 .19 abase name : Grassy_Site_Tallveg

Scanworlds

Scanworld 2

Scanworld 3

Scanworld 5
Scanworld 6

Constraints

TargetID:

TargetID: $B M 2$

TargetID: Targs

TargetID: $B M 1$

TargetID: $B M 2$

TargetID: BM3

TargetID: Targ5

TargetID: BMI

TargetID: $B M 2$

TargetID: Targ5

Targetro: BM3

Targetr: $\mathrm{BM} 1$

TargetID: BM4

TargetID: Targ5

TargetID: BM3

TargetID: BM2

TargetID: BM1

TargetID: ${ }^{\text {BM4 }}$ TargetID: Targ5

TargetID: $B M 3$

TargetID: $B M 2$

$\begin{array}{ll}\text { TargetID: BM4 } & \text { Scanworld } 5 \\ \text { TargetID: Targ5 } & \text { Scanworld } 5\end{array}$

Scanworld, Scanworld Scanworld Scanworld scanworld 2 scanworld scanworld 2 scanwor Scanworld scanworld 2 scanworld 2 scanworld Scanwor $7 d$ Scanworld 2 Scanworld Scanworld 3 scanworid scanworid Scanworid Scanworld Scanworld Scanworld Scanworld Scanworld Scanworld scanworld

Scanworld Transformations

Scanworld 2

transiation: $(0.000,0.000,0.000) \mathrm{m}$
rotation: $(0.0000,1.0000,0.0000): 0.000 \mathrm{deg}$

scanworld 3

translation: $(53.235,6.436,-2.173) \mathrm{m}$

rotation: (0.0052, 0.03i3, 0.9995):5.141 deg

Scanworld 5

translation: $(65.086,-87.740,-8.533) m$
rotation: (-0.0030, 0.0083, -1.0000$): 159.644 \mathrm{deg}$

Scanworld 6

transiation: $(9.095,-91.707,-6.572)$
rotation: $(-0.0008,0.0076,-1.0000): 170.336 \mathrm{deg}$

unused controlspace objects : none

Figure A4. Interim Registration Diagnostics_GS.txt
Type on/off coincident: vertex-vertex on coincident: vertex-vertex on coincident: vertex-vertex on coincident: vertex-vertex on Coincident: Vertex-vertex on coincident: vertex-vertex on coincident: vertex-vertex on Coincident: Vertex-vertex on Coincident: vertex-vertex on coincident: vertex-vertex on coincident: vertex-vertex on coincident: vertex-vertex on coincident: vertex-vertex on coincident: vertex-vertex on coincident: vertex-vertex on coincident: vertex-vertex on coincident: vertex-vertex on coincident: vertex-vertex on coincident: vertex-vertex on coincident: vertex-vertex on coincident: vertex-vertex on coincident: vertex-vertex on coincident: vertex-vertex on Coincident: vertex-vertex on

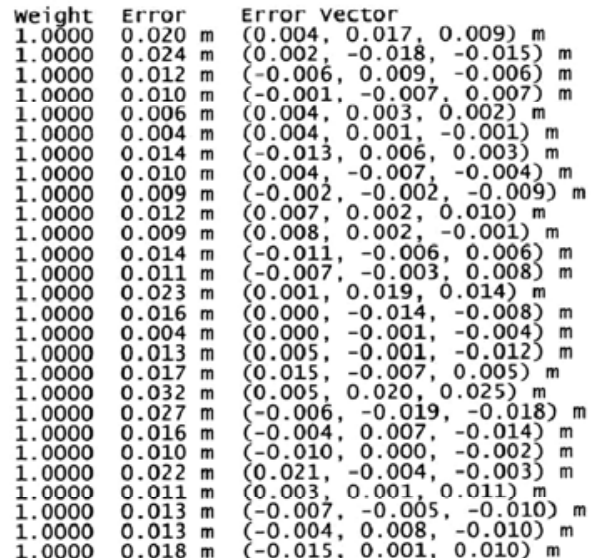


Appendix B
Cyra Scan Logs/Field Sketches 


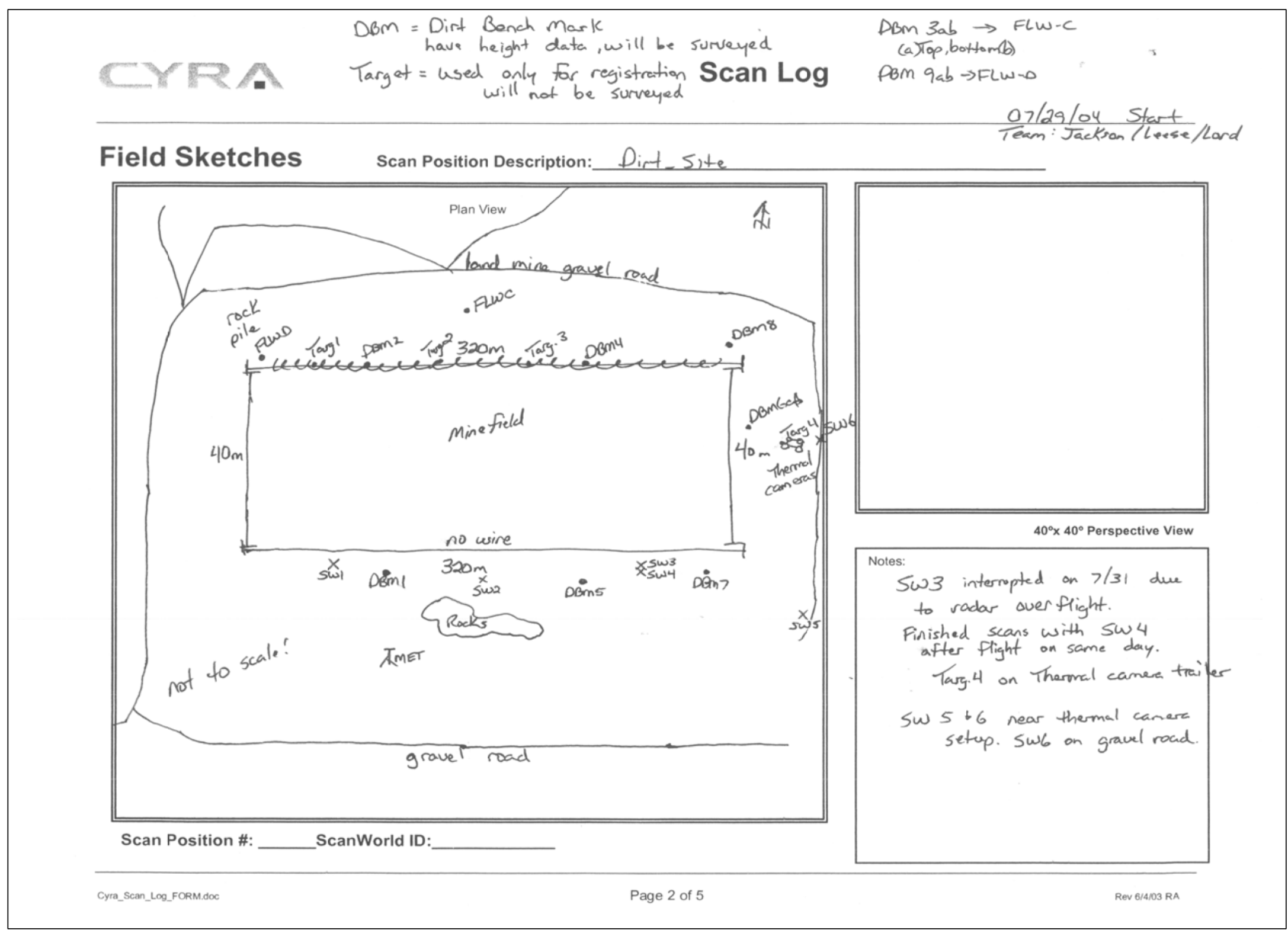

Figure B1. Cyra scan logs/field sketches (Sheet 1 of 16) 


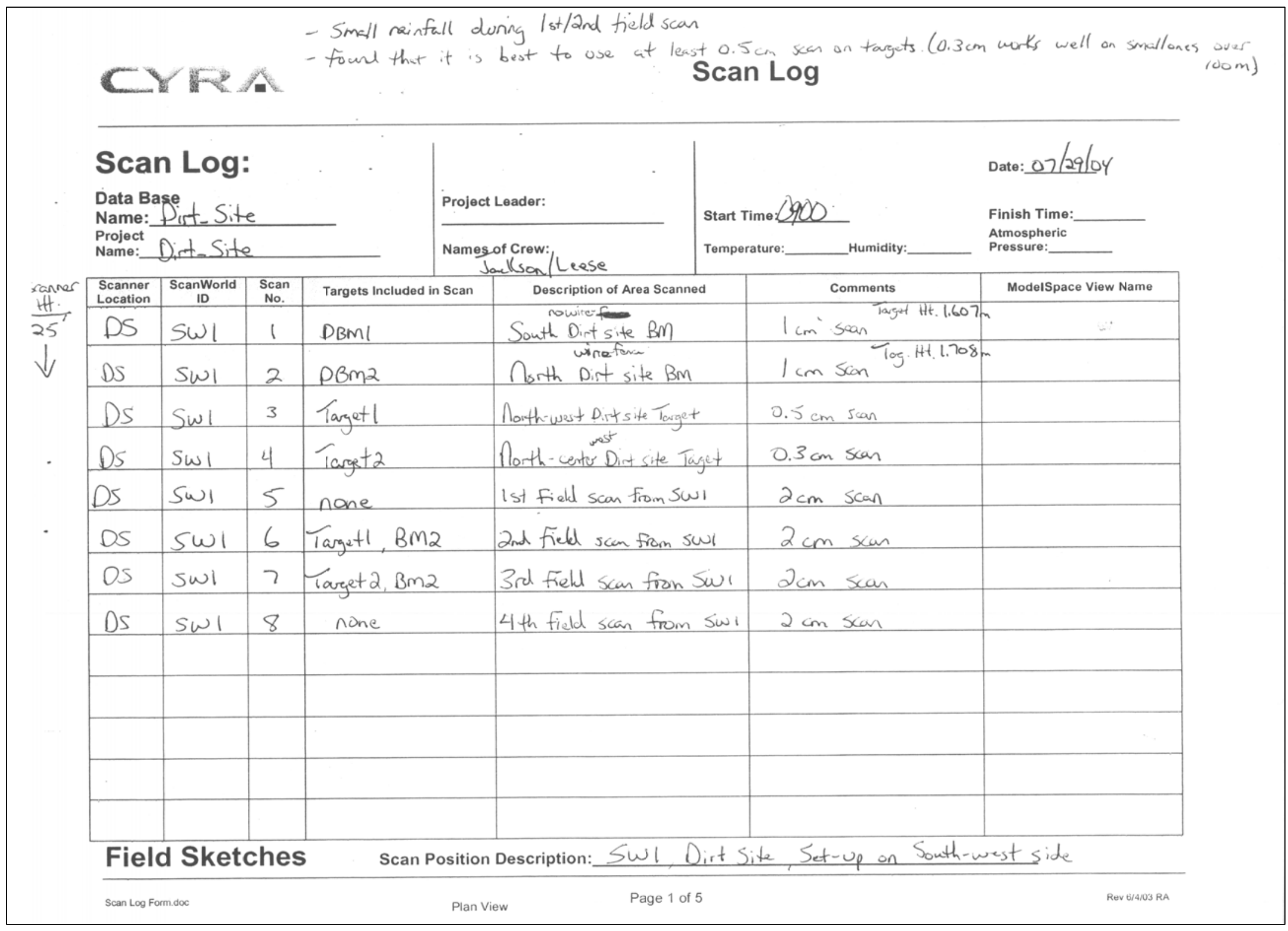




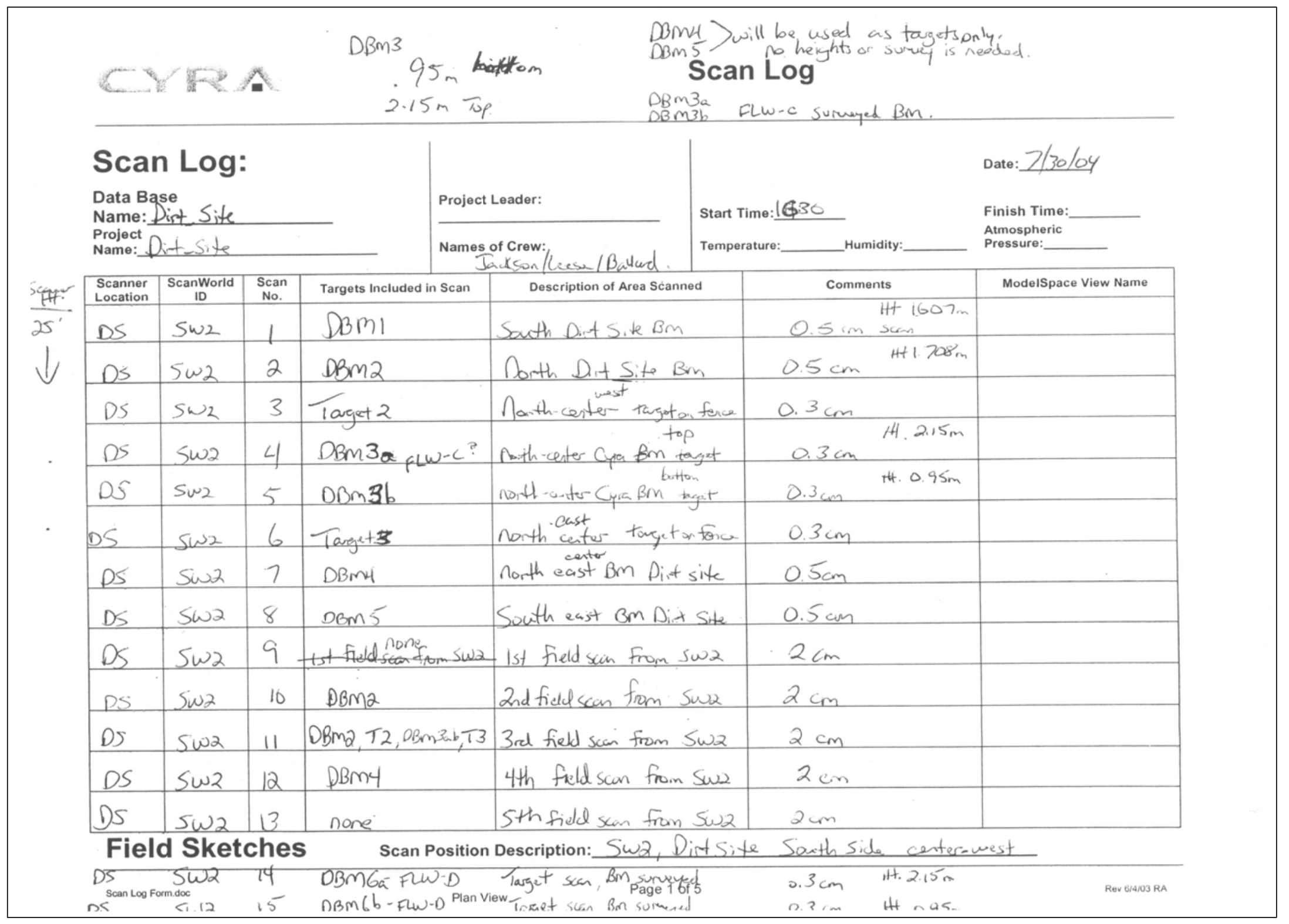

Figure B1. (Sheet 3 of 16) 


\section{CWMA Scan Log}

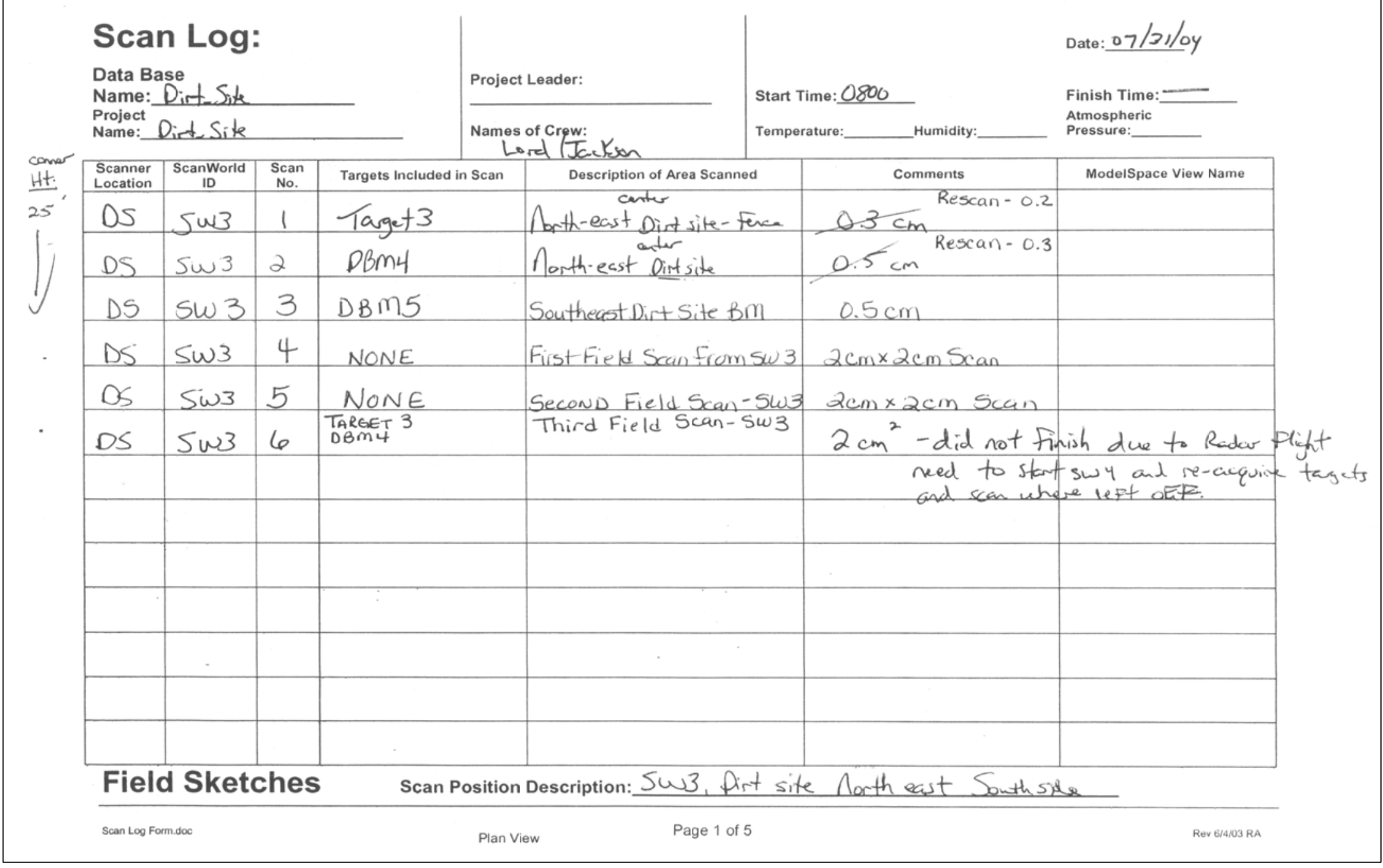




\section{Scan Log}

\section{Scan Log:}

Data Base

Name: Pirt Site

Project Dirt Site

scon

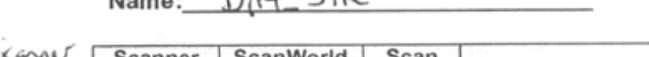

$\frac{\text { HA. }}{25^{-1}}$

U.

Field Sketches
Date: $27 / 3,104$

Project Leader:

Names of Crew:

Takson Lease/Bullad/thord

Finish Time:

Atmospheric

Jaukson/Leese/Bcllard/Lord

Atmospheric
Pressure:

\begin{tabular}{|c|c|c|c|c|c|c|}
\hline $\begin{array}{l}\text { Scanner } \\
\text { Location }\end{array}$ & $\begin{array}{c}\text { ScanWorld } \\
\text { ID }\end{array}$ & $\begin{array}{l}\text { Scan } \\
\text { No. }\end{array}$ & Targets Included in Scan & Description of Area Scanned & Comments & ModelSpace View Name \\
\hline $\mathrm{PS}_{\mathrm{SW}}$ & 504 & 1 & Fogat 3 & $\begin{array}{c}\text { corter } \\
\text { Morth-east Dist sike ferce }\end{array}$ & $0.3 \mathrm{~cm}$ & \\
\hline$S$ & SwH & 2 & DBHA 4 & North east Dist site & $0.3 \mathrm{~cm}$ & \\
\hline DS & $5 \omega 4$ & 3 & DBM5 & Southeast Dirt Site BM & $0.5 \mathrm{~cm}$ & \\
\hline Ds & $5 \omega 4$ & 4 & DBmba & East side of Dirf site & $0.2 \mathrm{~cm}$ & \\
\hline & Swy & 5 & $\operatorname{DBM} 6 b$ & $\begin{array}{l}\text { Cyia bottom } \\
\text { East sile of Dit site }\end{array}$ & $0.2 \mathrm{~cm} \mathrm{H.2.15 \textrm {m }}$ & \\
\hline DS & $5 w 4$ & 6 & $T_{\log _{2}+4}+4$ &  & $0.2 \mathrm{~cm}$ & \\
\hline DS & Sw4 & ᄀ & $\operatorname{Bgn} 4$ & Ist Field scan from $5 w 4$ & $2 \mathrm{~cm}$ & \\
\hline DS & sw4 & $a$ & NONE & $2^{\text {nd }}$ Field Scan from Sw 4 & $\begin{aligned} & 1114 \times 726 \\
& 2 \mathrm{~cm}(31.931 \mathrm{~m})\end{aligned}$ & \\
\hline DS & $5 w 4$ & 10 & $\begin{array}{l}\text { Tangct } 4, D B M 7 \\
0 B \text { S }\end{array}$ & $3^{\text {rd }}$ Field Scan - Eastend & $20 \mathrm{~m} \times 2 \mathrm{~cm}(26.915)$ & \\
\hline DS & Sw 4 & 11 & $\triangle B M 7$ & $\begin{array}{l}\text { Acquice newly placili trikiseT } \\
\text { South east conner-Bin wiver trec }\end{array}$ & $\begin{array}{l}2 \times 2 \\
\frac{5 \times 5}{9} 93.4 \\
\end{array}$ & \\
\hline & & & $D B M 8$ & $\begin{array}{l}\text { Acquire newly placed target } \\
\text { Noitheast corner Bm }\end{array}$ & $\begin{array}{l}0.3 \times 0.3 \mathrm{~cm}^{2} \mathrm{~V} \\
-5\end{array}$ & \\
\hline & & & & & & \\
\hline & & & & & & \\
\hline
\end{tabular}

Scan Position Description: Sw 4 , Southeast Dint fieil Site

Figure B1. (Sheet 5 of 16) 


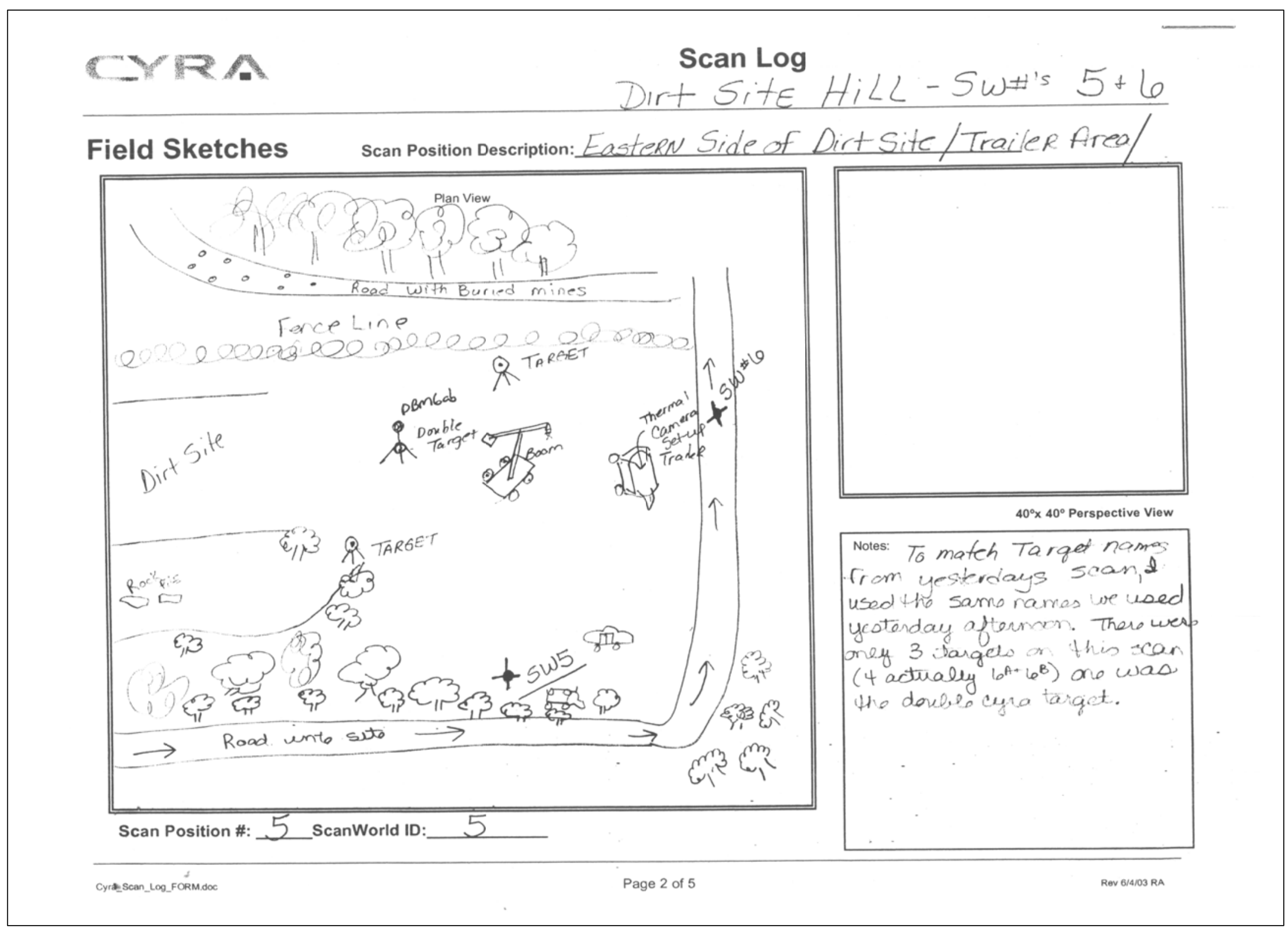




\section{A Scan Log}

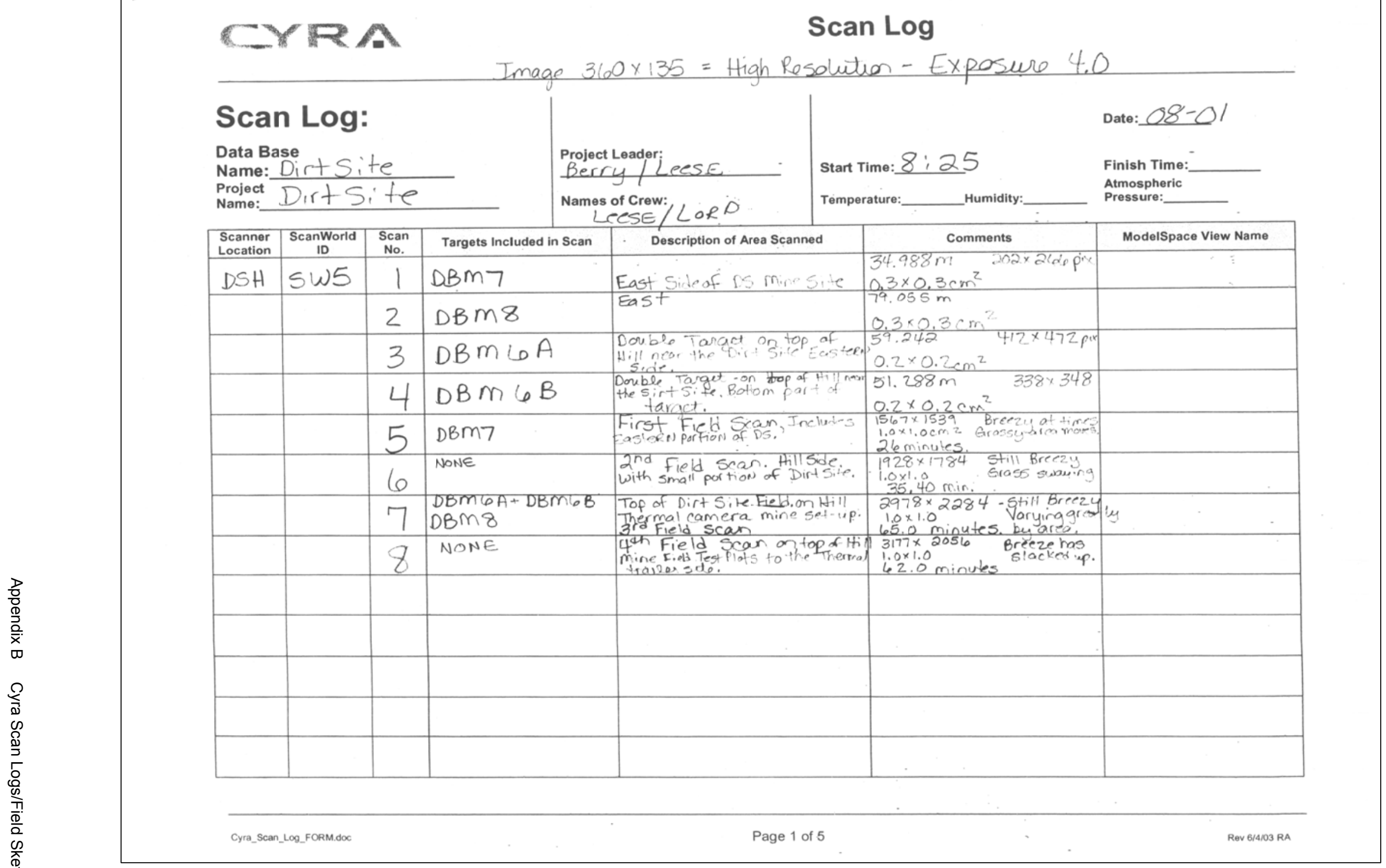

Figure B1. (Sheet 7 of 16) 


\section{Scan Log}

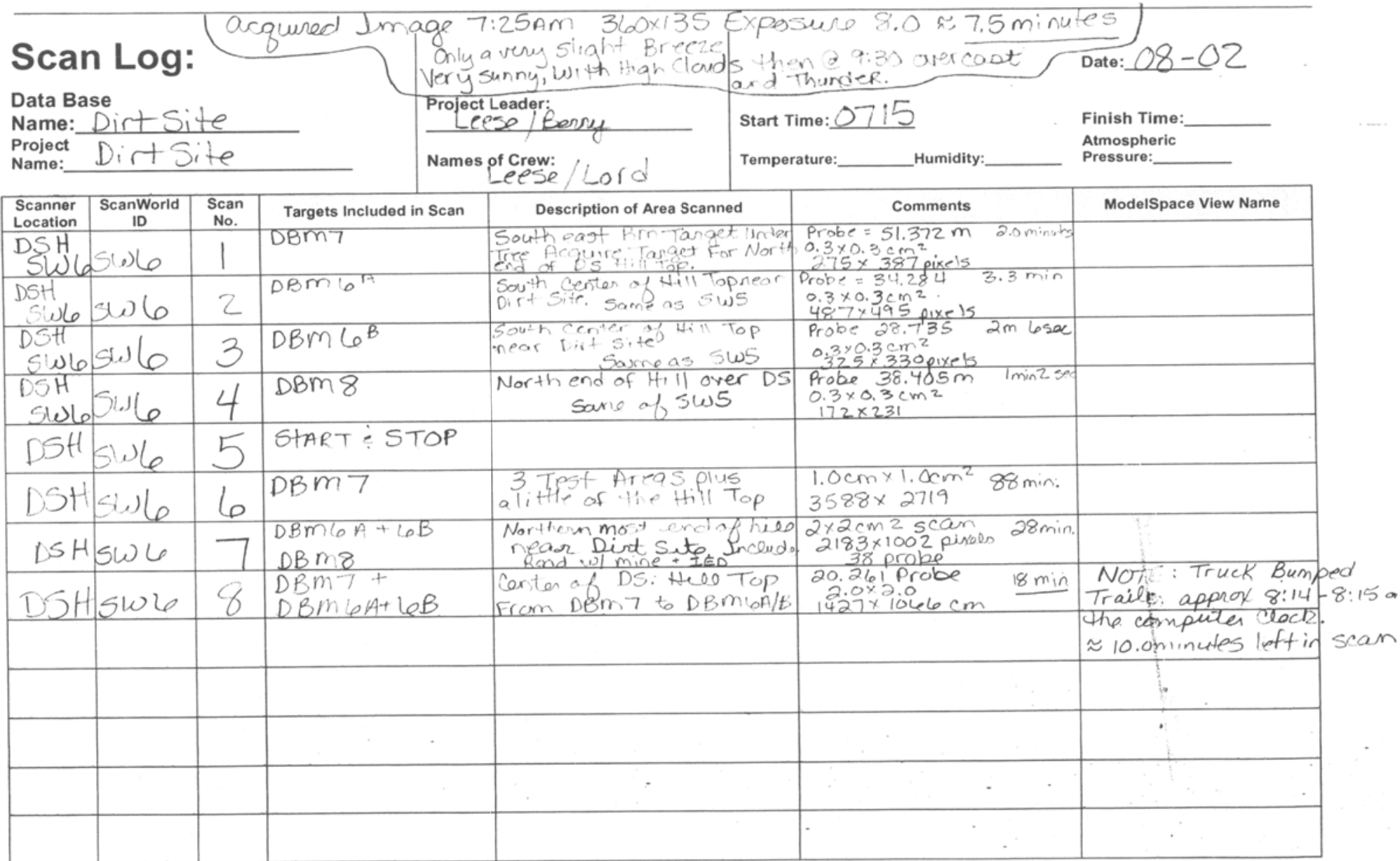

Cyra_SCan_Log_FORM.doc 


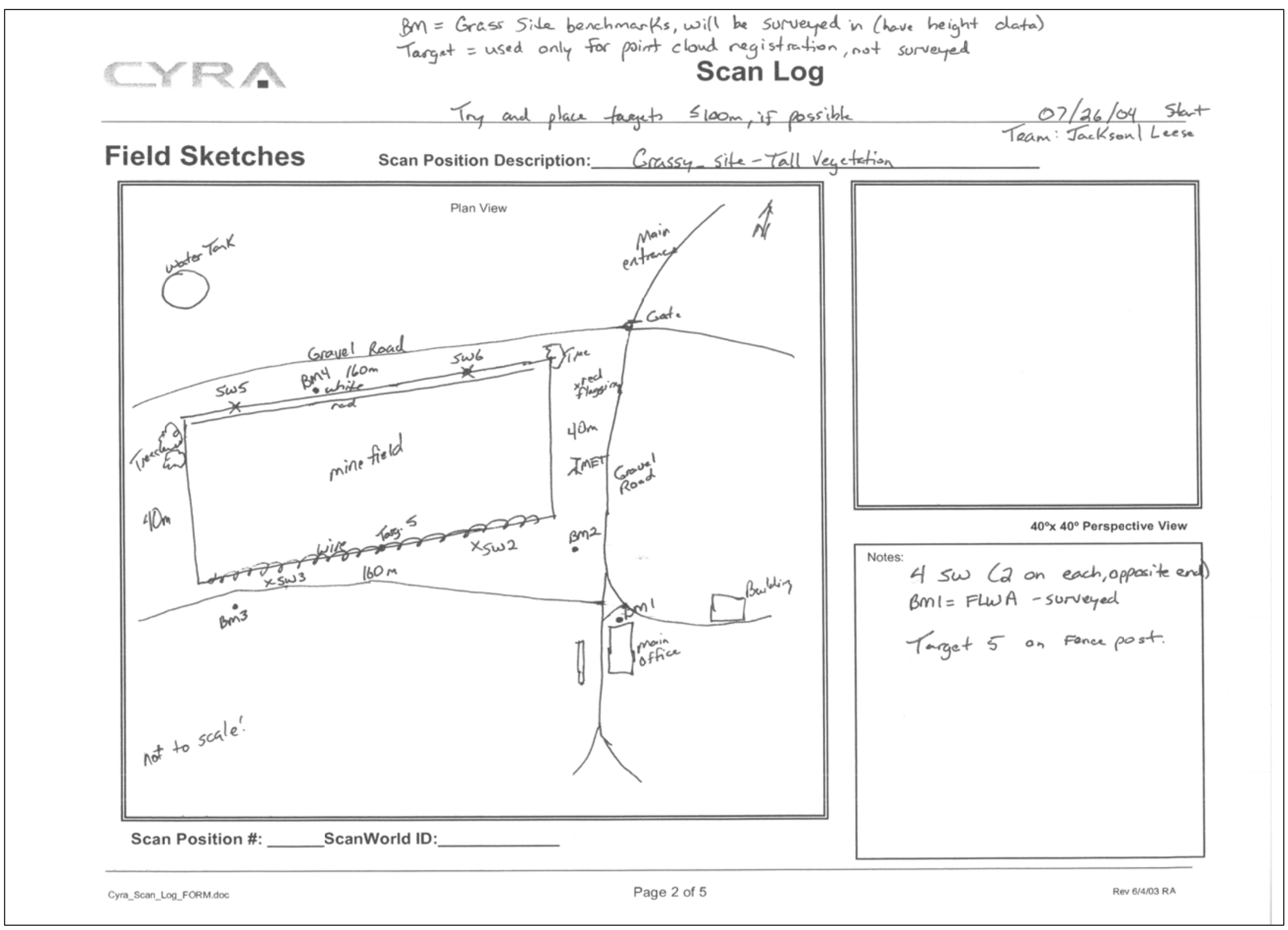

Figure B1. (Sheet 9 of 16) 


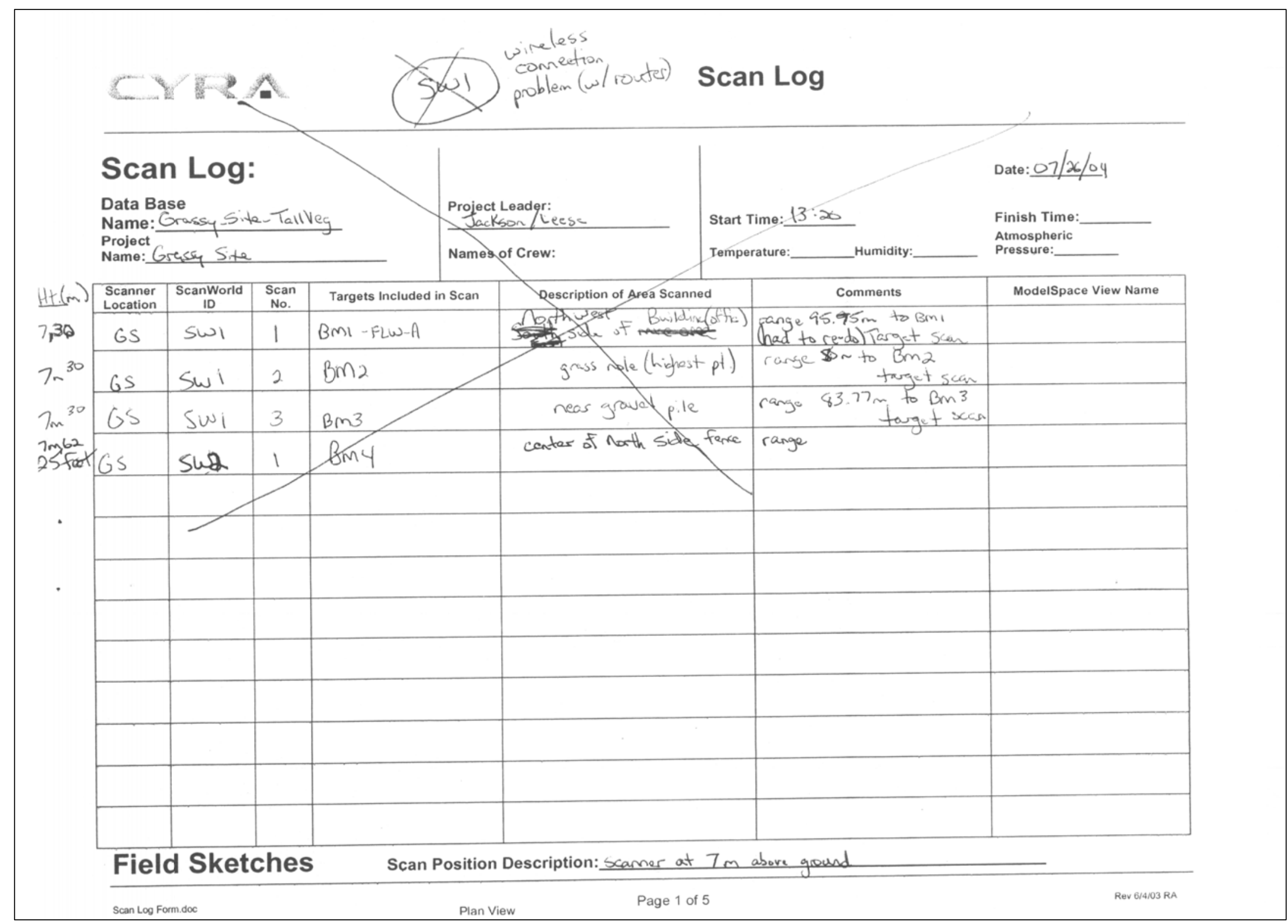


Scan Log

Allow $10 \%$ overkp b/t fietd scans

\section{Scan Log:}

Data Base

Name: Grassy_Site Kall Veg

Name:Crassy Site

zames

Leeso

Start Time: 1430 Finish Time:

Temperature:__ Humidity:

Pressure:-

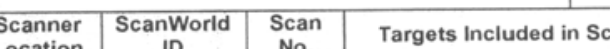

(2omments

\begin{tabular}{|l|l} 
ModelSpace View Name \\
\hline
\end{tabular}

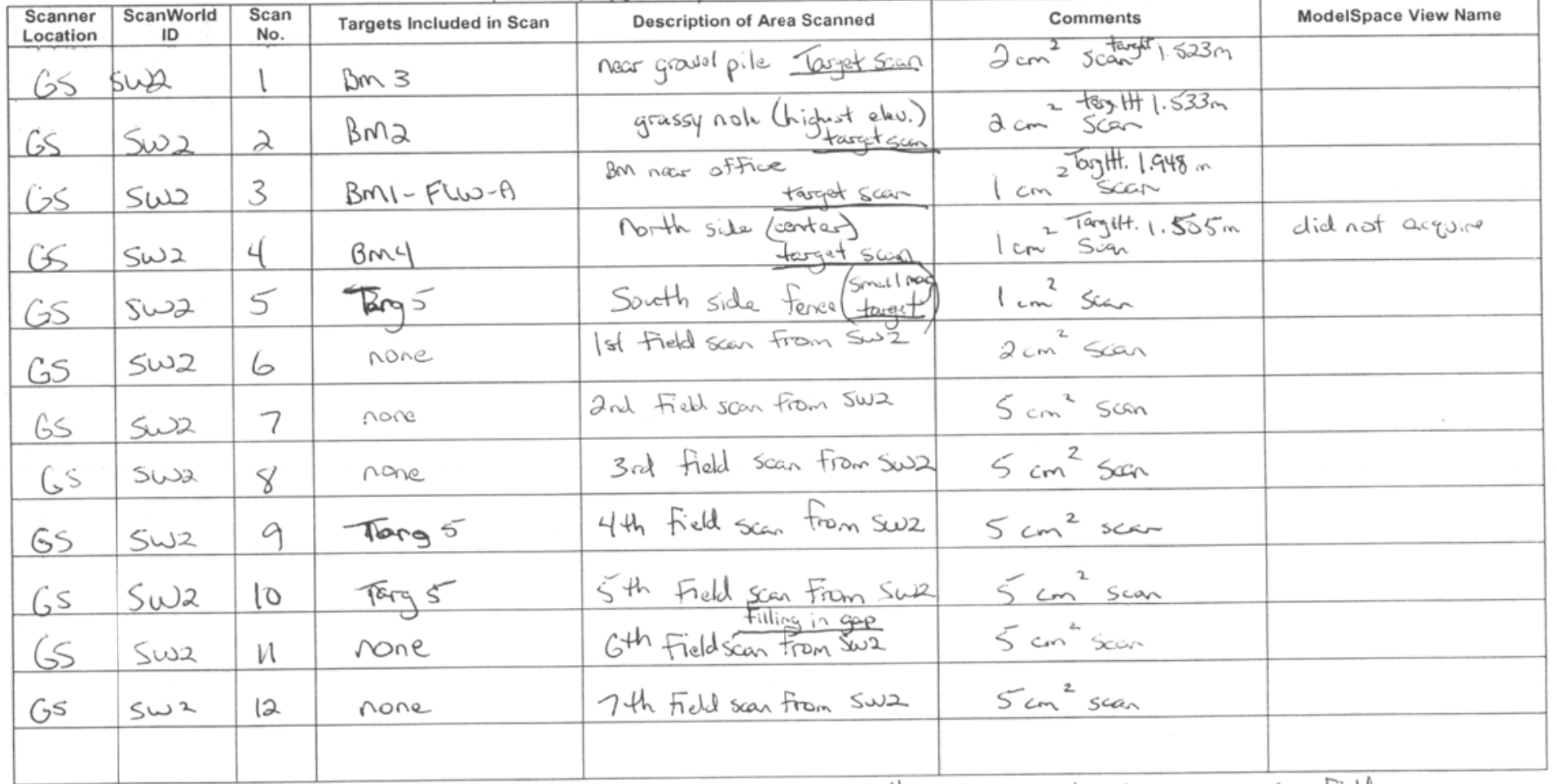

Field Sketches

Scan Position Description: Sw2 South-East towerter-in, grassy mine field

scan Log Form.doc

Plan View

Page 1 of 5

Rev 6/4/03 RA

Figure B1. (Sheet 11 of 16 ) 


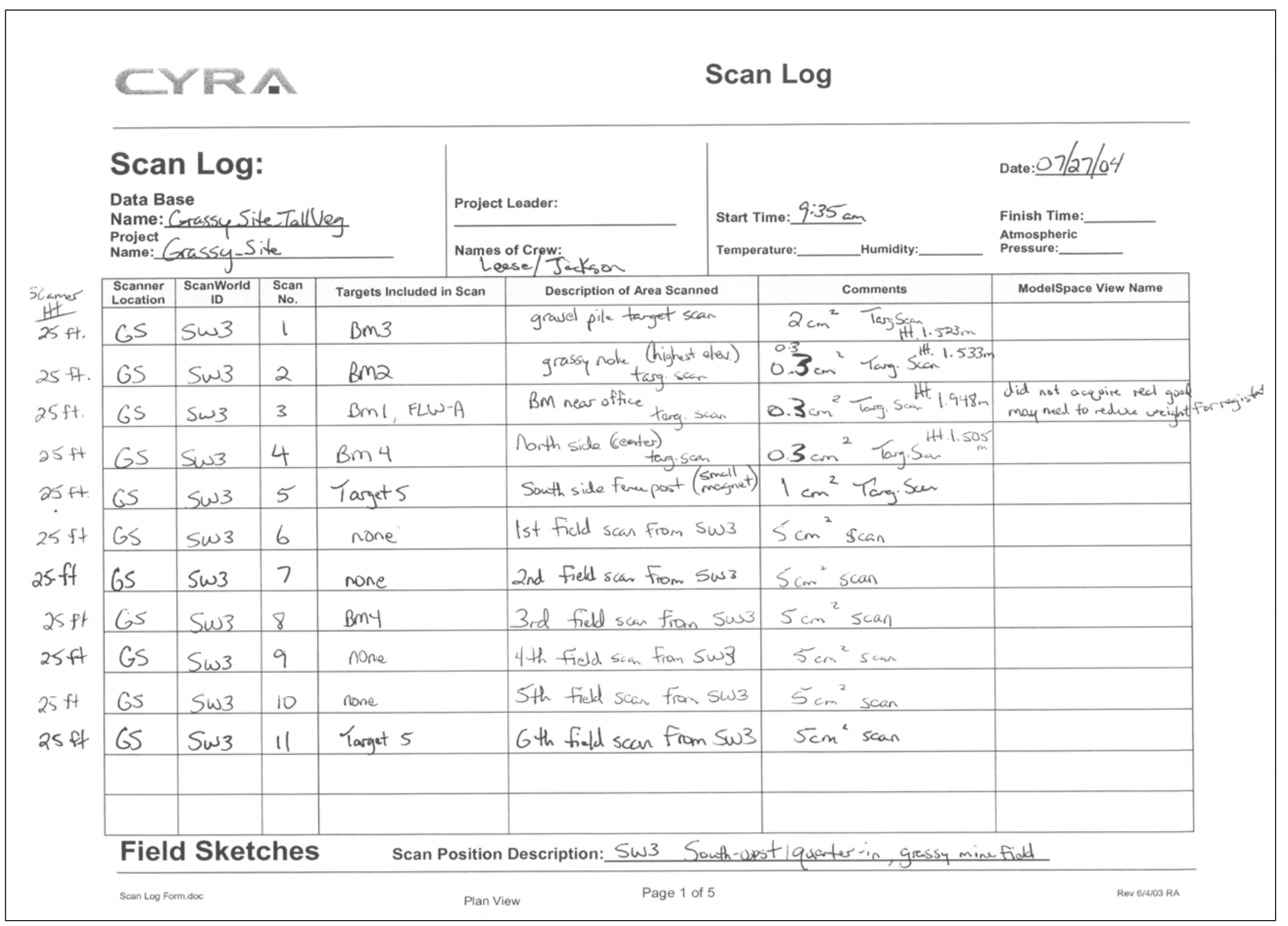




\section{Scan Log}

$$
\text { Re-Do! as } 5 \omega 6
$$

\section{Scan Log:}

Data Base

Name: Grassy-Site-TallVey

Name: Grassy Site

Re-Do! as $5 w 6$

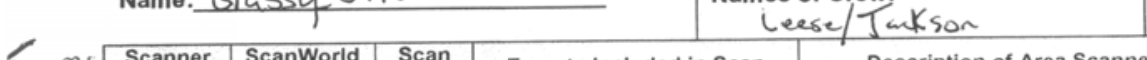

Start Time: $1400 / 1500$

Temperature:

Humidity:

Date: $07 / 22104 / R_{01 / 28 / 64}$

Finish Time: 1700 AS Finish Time:
Atmospheric
Pressure:

\begin{tabular}{|c|c|c|c|c|c|c|c|}
\hline Tougerer & \begin{tabular}{l|} 
Scanner \\
Location
\end{tabular} & \begin{tabular}{c|c} 
ScanWorld \\
ID
\end{tabular} & $\begin{array}{l}\text { Scan } \\
\text { No. }\end{array}$ & Targets Included in Scan & Description of Area Scanned & Comments & ModeISpace View Name \\
\hline $25 \mathrm{ft}$ & Gs & $5 w 4$ & 1 & BM3 & gravel pile-larget scan & $02 \mathrm{~cm}^{2}$ torget $1.41 .523 \mathrm{~m}$ & \\
\hline $26 \pi$ & GS & Sw 4 & 2 & Bm2 & grassy nole - highest elev. & $0.3 \mathrm{~cm}^{2}$ Tay ht. $1.533 \mathrm{~m}$ & \\
\hline $25 \mathrm{ft}$ & GS & Sw4 & 3 & $B M 1-F L W-A$ & Bn rew offor & $0.1 \mathrm{~cm}^{2}$ tanght $1.948 \mathrm{~m}$ & didnot acquine \\
\hline $25 \mathrm{ft}$ & Gs & Sw4 & 4 & Bm4 & North ferce-center & $0.5 \mathrm{~cm}^{2}+t a y g h t 1.505 \mathrm{~m}$ & \\
\hline $25 \mathrm{ft}$ & GS & Sw4 & 5 & Target 5 & South five contes magnet taget. & $0.3 \mathrm{~cm}^{2}$ scan-tayet & \\
\hline $25 \mathrm{ft}$ & G5 & Sw4 & 6 & none & Ist field soun from swt & $5 \mathrm{~cm}^{2} \mathrm{Sca}$ & \\
\hline $2 \leq+f t$ & GS & $5 \omega 4$ & 7 & none & 2nd field som fion susy & $5 \mathrm{~cm}^{2} \operatorname{scan}$ & \\
\hline $25 \mathrm{ft}$ & 65 & sw4 & 8 & none & 3rd find sus from suly & $5 \mathrm{~cm}^{2} \mathrm{sean}$ & \\
\hline $25 \mathrm{ft}$ & GS & Sw4 & $q$ & none & 4th field scon fiom Sw 4 & $5 \mathrm{~cm}^{2} \operatorname{sear}$ & \\
\hline $25+7$ & G5 & Swy & 10 & targat 5/Bin 3 & 5th field scan from Sw4 & $\operatorname{Som}^{2} \operatorname{scan}$ & \\
\hline $25 \mathrm{ft}$ & CS & Swy & 11 & $\mathrm{Bm}^{3}$ & 6th field scan from swy & $5 \mathrm{~cm}^{2} \mathrm{scan}$ & \\
\hline $25 \mathrm{ft}$ & GS & $5 w 4$ & 12 & none & 7 th field scan from sw4 & $5 \mathrm{~cm}^{2} \mathrm{sean}$ & \\
\hline $25 p t$ & GS & swy & 13 & $B m 4$ & 8th field sain from swy & $5 \mathrm{~cm}^{2} \operatorname{scar}$ & \\
\hline
\end{tabular}

Field Sketches

$25 \mathrm{ft}$ GS Scan Log Form.doc none Scan Position Description: Sw4 North-easti quaster in, grassy minefrobl 


\section{CYRA}

\section{Scan Log:}

Data Base

Name: Grassy Site Tell Vey

Name:Grassy-Site

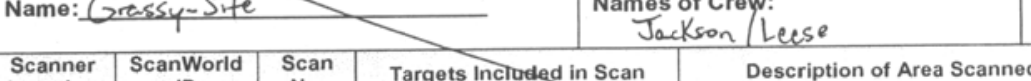

\begin{tabular}{|c|c|c|c|c|c|c|}
$\begin{array}{c}\text { Scanner } \\
\text { Location }\end{array}$ & $\begin{array}{c}\text { ScanWorld } \\
\text { ID }\end{array}$ & $\begin{array}{c}\text { Scan } \\
\text { No. }\end{array}$ & Targets Included in Scan & Description of Area Scanned & Comments & ModelSpace View Name \\
\hline
\end{tabular}

\begin{tabular}{|c|c|c|c|c|} 
Location & ID & No. & Comments & $\mathrm{cm}^{2}$ taget $^{\text {Ht }} 1.523 \mathrm{~m}$
\end{tabular}

\begin{tabular}{|c|c|c|c|c|c|}
\hline GS & Sw5 & 1 & $\mathrm{Bm} 3$ & gravel pile & s. \\
\hline GS & Sw 5 & 2 & Bma & & i $\mathrm{cm}^{2}$ target scan \\
\hline
\end{tabular}

GS

GS SwS 3 BMI-FLW-A

GS SW5 4 Bin 4 north-centur fence

\begin{tabular}{l|l|l|l|l}
\hline 65 & $5 \omega 5$ & 5 & Target 5 \\
\hline
\end{tabular}

\begin{tabular}{|l|l|l|l|l|l|l|}
\hline & & & & & & \\
\hline & & & & & & \\
\hline & & & & & & \\
\hline & & & & & & \\
\hline & & & & & & \\
\hline
\end{tabular}

Field Sketches

Scan Position Description 


\section{C $\mathrm{Cr}$ Scan Log}

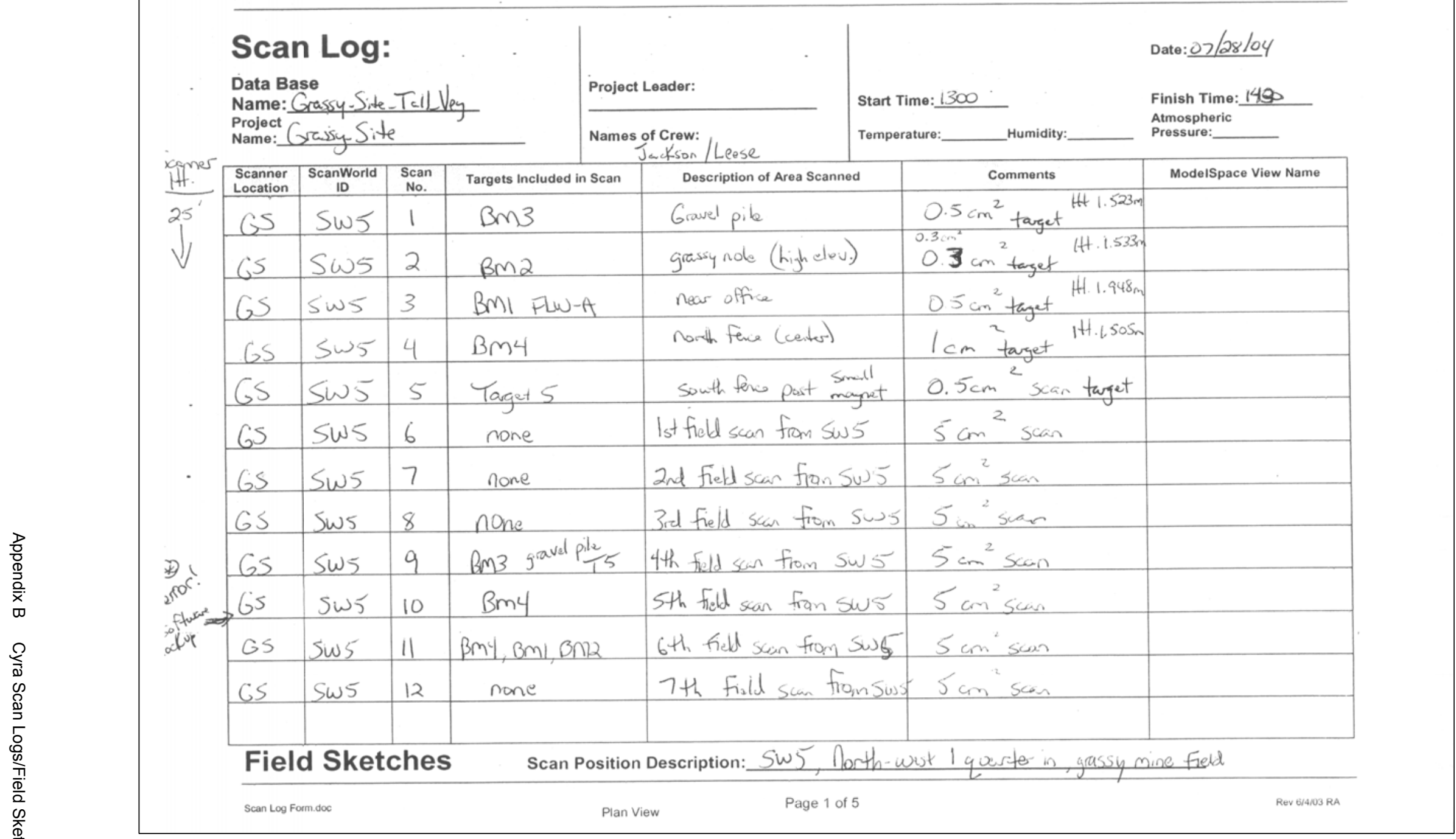

Figure B1. (Sheet 15 of 16) 


\section{Scan Log}

\section{Scan Log:}

Data Base

Name: GRASS SITE

Project GRASSYSUE. TPRe VÉr

Name: SACKGa/LEESE

\begin{tabular}{|c|c|c|c|c|c|c|}
\hline Location & ID & No. & & & & \\
\hline GS & $5 W / 4 C$ & 1 & $B n_{3}$ & Graver Pice BM & $0.5 a-1.523 \mathrm{~m}$ & \\
\hline 45 & Swl 6 & 2 & $B M Z$ & GaAtesn lavere & $0.5 \mathrm{Cm} \quad \begin{array}{l}\text { TalCENH } \\
1.533\end{array}$ & \\
\hline 65 & 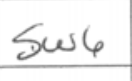 & 3 & $B m 1$ & $A P G 1-$ & $0.2^{11.948}$ & \\
\hline S & Sw6 & 4 & $\mathrm{Bm} 4$ & Nolth Fance - conts & $0.8 \mathrm{em} 1.505$ & 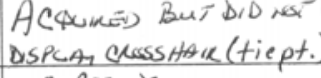 \\
\hline
\end{tabular}

Start Time: $/ 500 \quad$ Finish Time: 1830

Temperature:__ Humidity:___ Pressure:_

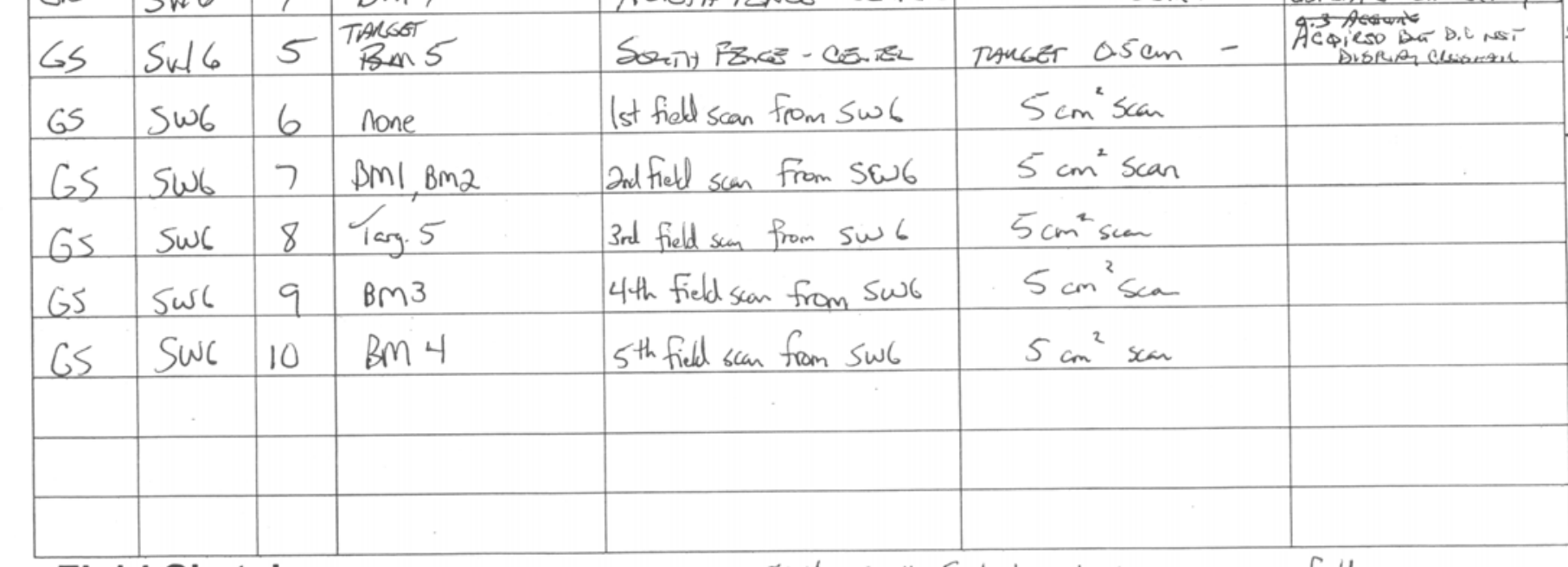

lackel up of setiong Via acquir torg. as tie point software closed by itself

Field Sketches

Scan Position Description: SWl Necth East I quenter-in, grassy mine field

Scan Log Form.doc

Plan View

Page 1 of 5

Rev 6/403 RA 


\section{Appendix C Scanner Setup Pictures}

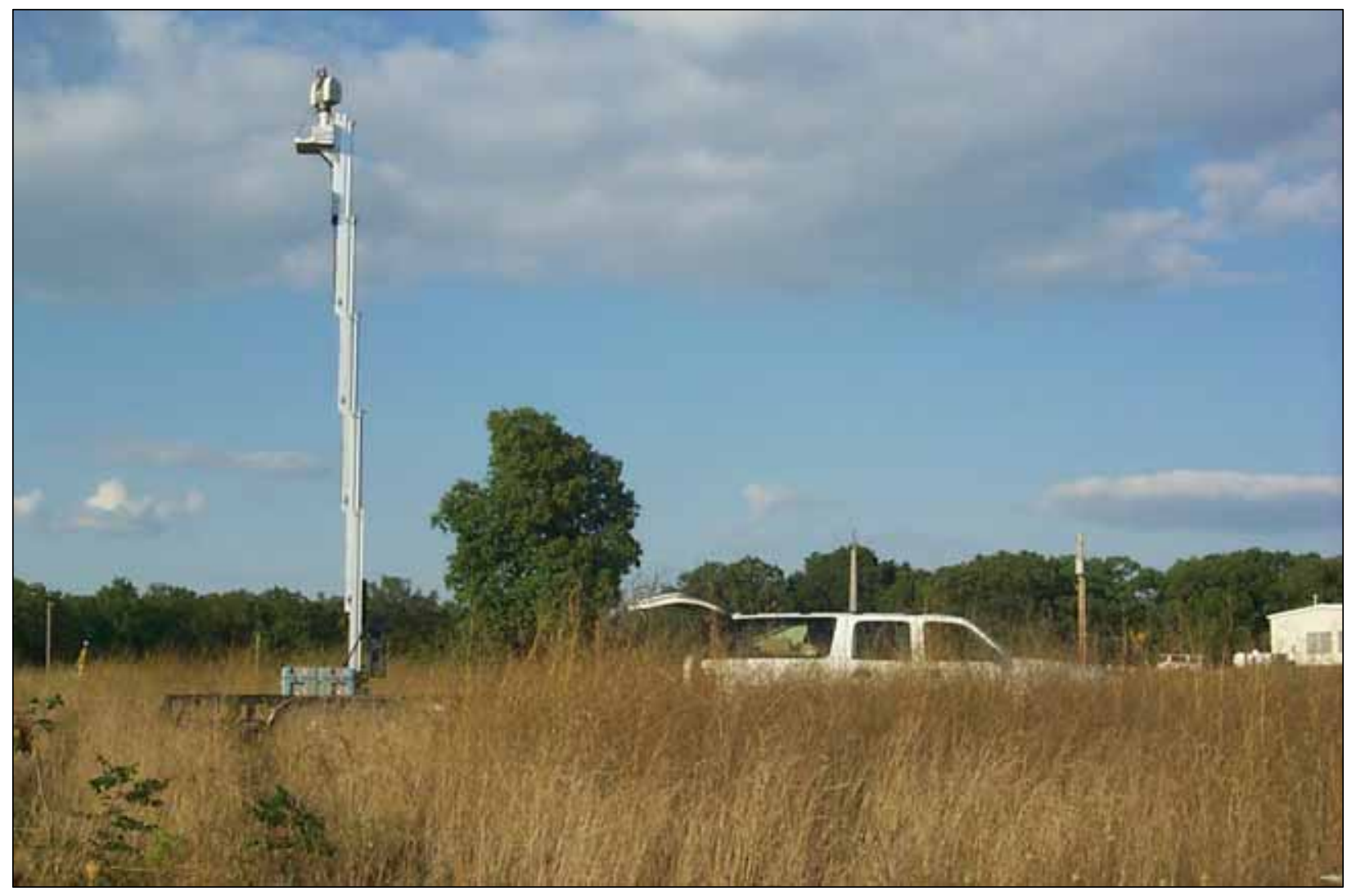

Figure C1. Trailer-mounted setup of Leica HDS3000 3D Laser Scanner elevated $7.62 \mathrm{~m}$ above Grass Site (viewed from southwest looking northeast, taken 26 July 2004) 


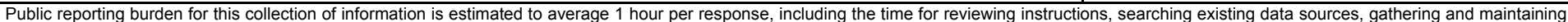

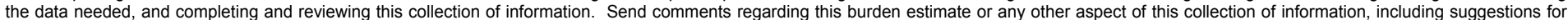

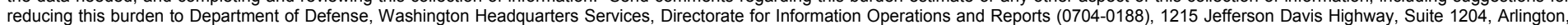

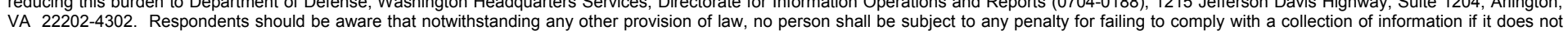
VA 22202-4302. Respondents should be aware that notwithstanding any other provision of law, no person shall be sube
display a currently valid OMB control number. PLEASE DO NOT RETURN YOUR FORM TO THE ABOVE ADDRESS.

\begin{tabular}{l|c}
$\begin{array}{l}\text { 1. REPORT DATE (DD-MM-YYYY) } \\
\text { August } 2005\end{array}$ & $\begin{array}{c}\text { 2. REPORT TYPE } \\
\text { Final report }\end{array}$ \\
\hline
\end{tabular}

\section{TITLE AND SUBTITLE}

Use of a High-Resolution 3D Laser Scanner for Minefield Surface Modeling and

Terrain Characterization: Temperate Region

3. DATES COVERED (From - To)

5a. CONTRACT NUMBER

5b. GRANT NUMBER

5c. PROGRAM ELEMENT NUMBER

\section{AUTHOR(S)}

Sam S. Jackson, Michael J. Bishop 5d. PROJECT NUMBER

5e. TASK NUMBER

5f. WORK UNIT NUMBER

8. PERFORMING ORGANIZATION REPORT NUMBER

ERDC/EL TR-05-9

U.S. Army Engineer Research and Development Center

Environmental Laboratory

3909 Halls Ferry Road

Vicksburg, MS 39180-6199

\section{SPONSORING / MONITORING AGENCY NAME(S) AND ADDRESS(ES)}

U.S. Army Corps of Engineers

Washington, DC 20314-1000

10. SPONSOR/MONITOR'S ACRONYM(S)

11. SPONSOR/MONITOR'S REPORT NUMBER(S)

\section{DISTRIBUTION / AVAILABILITY STATEMENT}

Approved for public release; distribution is unlimited.

\section{SUPPLEMENTARY NOTES}

\section{ABSTRACT}

The use of a high-resolution, ground-based 3D laser scanner was recently evaluated for terrestrial site characterization of variablesurface minefield sites and generation of surface and terrain models. The instrument used to conduct this research was a Leica HDS3000 3D laser scanner. The high-speed, highly accurate ranging system has a $360 \mathrm{deg}$ horizontal $\times 270$ deg vertical field of view that delivers positional, range, and angular (vertical and horizontal) single point accuracies (range 1 to $50 \mathrm{~m}$ ) of $6 \mathrm{~mm}, 4 \mathrm{~mm}$, and $60 \mathrm{micro}-\mathrm{radians}$, respectively. The laser is a class $3 \mathrm{R}$ and is completely eye-safe with a wavelength of $523 \mathrm{~nm}$ and spot size of $\leq 6 \mathrm{~mm}$ at a distance of 50 $\mathrm{m}$. The pulse rate is 1,000 points/sec with an optimal effective range up to $100 \mathrm{~m}$ which is capable of producing a maximum point cloud spacing of $1.2 \mathrm{~mm}$ in the horizontal and vertical direction. Two study sites located in the midwestern United States were used for this analysis. A very dense vegetation site (Grass Site) and a bare soil site with intermittent rocks and sparse vegetation (Dirt Site) were selected for data collection to simulate both obscured and semi-obscured minefield sites. High-density scans (range 0.2 to $2.0 \mathrm{~cm}$ spacing) were utilized for Cyra target acquisition and were commensurate with size and distance to target from scanner location. Medium-density scans (range 2.0 to $5.0 \mathrm{~cm}$ spacing) were chosen for point cloud generation of the entire site(s) with approximately 10 percent edge overlap between field scans. In order to provide equivalent, unobstructed viewing perspectives from all scan locations

\section{SUBJECT TERMS}

Laser

LIDAR

16. SECURITY CLASSIFICATION OF:

a. REPORT

UNCLASSIFIED

b. ABSTRACT
UNCLASSIFIED

Minefield Modeling c. THIS PAGE UNCLASSIFIED (Continued)

Registration

\begin{tabular}{|c|c|}
\hline $\begin{array}{c}\text { 17. LIMITATION } \\
\text { OF ABSTRACT }\end{array}$ & $\begin{array}{c}\text { 18. NUMBER } \\
\text { OF PAGES }\end{array}$ \\
SAR & 44 \\
&
\end{tabular}

19a. NAME OF RESPONSIBLE PERSON

19b. TELEPHONE NUMBER (include area code) Stanc 


\section{4. (Concluded)}

at each site, the scanner was positioned on a trailer-mounted, chain-driven lift and raised to an approximate scan height of $7.6 \mathrm{~m}$ above the ground. Final registration to UTM projected coordinate system of the multiple scan locations for the Dirt Site and Grass Site produced mean absolute errors of 0.014 and $0.017 \mathrm{~m}$, respectively. The laser scanner adequately characterized surface roughness and vegetation height to produce contour and terrain models for the respective site locations. The detailed scans of the sites, along with the inherent natural vegetation characteristics present at each site, provide real-time discrimination of minefield site components under contrasting land surface conditions. 